\title{
Oxidative Mineralization and Characterization of Polyvinyl Alcohol for Compatibility with Tank Farm Processing Chemistry
}

by

L. N. Oji

Westinghouse Savannah River Company

Savannah River Site

Alken, South Carolina 29808

This paper was prepared in connection with work done under the above contract number with the U.S.

Department of Energy. By acceptance of this paper, the publisher and/or recipient acknowledges the U. S. Government's right to retain a nonexclusive, royalty-free license in and to any copyright covering this paper, along with the right to reproduce and to authorize others to reproduce all or part of the copyrighted paper. 
WESTINGHOUSE SAVANNAH RIVER COMPANY

SAVANNAH RIVER TECHNOLOGY CENTER

WSRC-RP-99-00524, Rev 0.0

Keywords: Polyvinyl acetate, Peroxide oxidation, UV

Photolysis \& Sonochemistry,

Permanganate oxidation

Decontamination.

Retention Time: Permanent

OXIDATIVE MINERALIZATION AND CHARACTERIZATION OF

POLYVINYL ALCOHOL FOR COMPATIBILITY WITH TANK FARM

PROCESSING CHEMISTRY (U).

Author: Lawrence N. Oji 773-43A

Report Date: June 30, 1999

Westinghouse Savannah River Company

Savannah River Site

Aiken. SC 29808

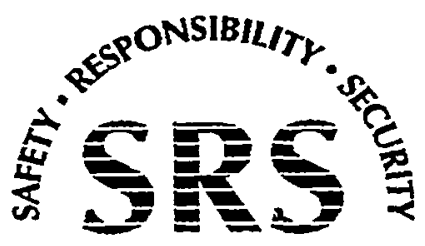


WESTINGHOUSE SAVANNAH RIVER COMPANY

SAVANNAH RIVER TECHNOLOGY CENTER

WSRC-RP-99-00524, Rev 0.0

Keywords: Polyvinyl acetate, Peroxide oxidation,UV

Photolysis \& Sonochemistry,

Permanganate oxidation

Decontamination.

Retention Time: Permanent

OXIDATIVE MINERALIZATION AND CHARACTERIZATION OF POLYVINYL ALCOHOL FOR COMPATIBILITY WITH TANK FARM

PROCESSING CHEMISTRY (U).

Author: Lawrence N. Oji 773-43A

Report Date: June 30, 1999

Westinghouse Savannah River Companv Savannah River Site Aiken. SC 29808

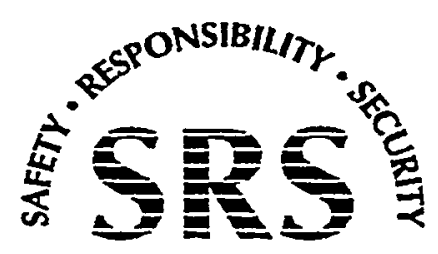




\section{DISCLAIMER}

This report was prepared as an account of work sponsored by an agency of the United States Government. Neither the United States Government nor any agency thereof, nor any of their employees, makes any warranty, express or implied, or assumes any legal liability or responsibility for the accuracy, completeness, or usefulness of any information, apparatus, product, or process disclosed, or represents that its use would not infringe privately owned rights. Reference herein to any specific commercial product, process, or service by trade name, trademark, manufacturer, or otherwise does not necessarily constitute or imply its endorsement, recommendation, or favoring by the United States Government or any agency thereof. The views and opinions of authors expressed herein do not necessarily state or reflect those of the United States Government or any agency thereof.

This report has been reproduced directly from the best available copy.

Available to DOE and DOE contractors from the Office of Scientific and Technical Information, P.O. Box 62, Oak Ridge, TN 37831; prices available from (615) 576-8401.

Available to the public from the National Technical Information Service, U.S. Department of Commerce, 5285 Port Royal Road, Springiield, VA 22161. 


\section{DISCLAIMER}

Portions of this document may be illegible in electronic image products. Images are produced from the best available original document. 
WESTINGHOUSE SAVANNAH RIVER COMPANY

SAVANNAH RIVER TECHNOLOGY CENTER

OXIDATIVE MINERALIZATION AND CHARACTERIZATION OF

POLYVINYL ALCOHOL FOR COMPATIBILITY WITH TANK FARM

PROCESSING CHEMISTRY (U).

Author

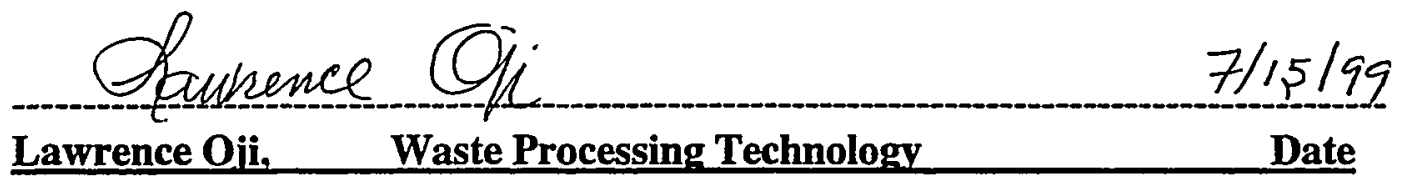

Design Check
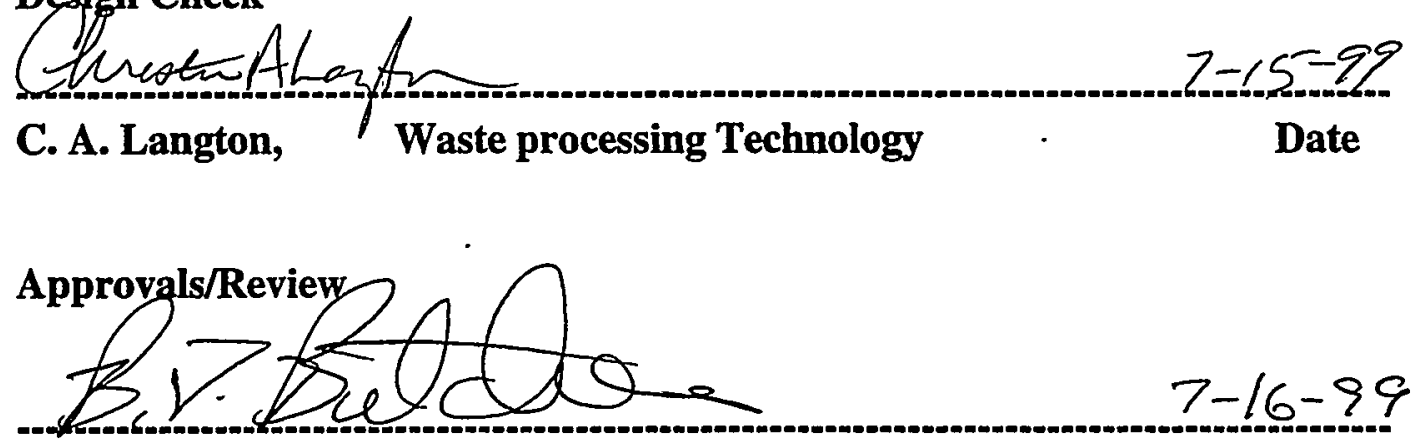

B.T. Butcher, Level 4 Manager, Waste Processing Technology Date

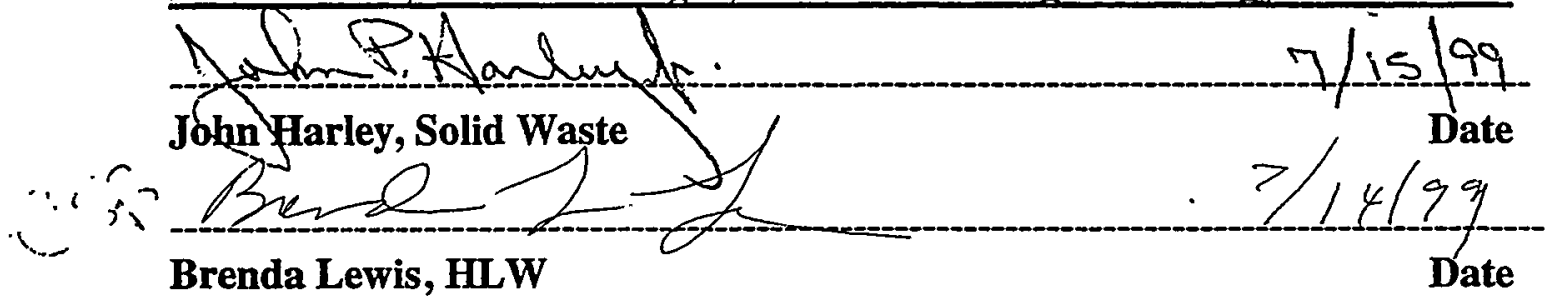



POLYVINYL ALCOHOL FOR COMPATIBILITY WITH TANK FARM PROCESSING CHEMISTRY (U).

\section{SUMMARY}

Polyvinyl alcohol (PVA) material has been evaluated for use as a cost-effective substitute for conventional cellulose-based disposal materials (decontamination mops and wipes), plastic bags, and disposable personal protection clothing, that are currently used at Savannah River site. These PVA materials, after use, can be dissolved in hot water to minimize treatment and disposal cost. The resulting PVA organic solution from such dissolution of the PVA material does not meet the Waste Acceptance Criteria (WAC) for SRS liquid waste processing facilities like the High level WasteTank Farm process. The main WAC problem is the high organic content of PVA solution. All other unwanted evaporation problems of PVA solution waste, such as "skin" formation and pumpability can be attributed to the high organic content of unadulterated PVA-based liquid waste. If PVA is chemically degraded to simpler organic compounds, it then becomes possible to treat such PVA based waste through SRS liquid waste treatment facilities without running into processing problems and other difficulties. Therefore, a new PVA chemical degradation process will have to be developed and tested before Tank Farm can accept PVA-based waste streams.

Ultraviolet photochemical and ultrasonic treatment of PVA in the presence of hydrogen peroxide was chosen as the primary method of PVA degradation. Oxidation of PVA with potassium permanganate in an aqueous matrix was also investigated. Oxidation of PVA with hydrogen peroxide is recommended because no solid particles are formed in the mixing and blending of oxidized PVA with Tank Farm simulants. The disappearance of PVA in hydrogen peroxide with ultrasonic and ultraviolet irradiation treatment was characterized by pseudo-first order reaction kinetics.

PVA-based waste is compatible with Tank Farm processing and chemistry only when the PVA is more than $90 \%$ oxidized with hydrogen peroxide or potassium permanganate. In addition, the efficiency of ion exchange resins and cesium precipitation agents (Crystalline Silicotitanate, Monosodium titanate and tetraphenyl borate) used for the uptake of radionuclids (cesium-137, strontium-90 and plutonium) from waste treatment facilities like the Tank Farms is not affected by the presence of oxidized PVA.

This study also provides process design criteria for ultraviolet/ultrasonic/hydrogen peroxide PVA reactor system. Benchmark and pilot scale studies are recommended for additional process optimization prior to operational deployment. 
OXIDATIVE MINERALIZATION AND CHARACTERIZATION OF POLYVINYL ALCOHOL FOR COMPATIBILITY WITH TANK FARM PROCESSING CHEMISTRY (U).

CONTENTS

\begin{tabular}{lr} 
Executive Summary & 3 \\
Contents & 4 \\
List of Figures & 5 \\
List of Tables & 5 \\
Introduction & 6 \\
Experimental & 7 \\
\multicolumn{1}{c}{ Approach } & 7 \\
$\quad$ Methods $\quad$ PVA Calibration Curve & 8 \\
\hline
\end{tabular}

PVA oxidation with potassium permanganate 11

Oxidation with permanganate crystals 11

Oxidation with acidified permanganate 13

Sonochemical/photochemical oxidation 15

Oxidation with hydrogen peroxide only 16

$366 \eta \mathrm{m}$ Photochemical oxidation with /without sonication 17

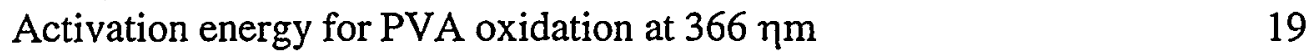

$302 \eta \mathrm{m}$ Photochemical oxidation with /without sonication 21

Oxidation products from photochemical/sonochemical treatment 21

Estimation of salt produced from $\mathrm{pH}$ adjustment of oxidized PVA 22

Evaporation/Mixing properties of Tank Farm simulant with oxidized PVA . 25

Ion exchange performance in the presence of oxidized PVA 27

Complexing and hydrolysis of radionuclides with oxidized PVA 28

Total organic volume per liter of oxidized PVA solution. 28

$\begin{array}{ll}\text { Discussions and Conclusions } & 29\end{array}$

Recommendations and Path Forward 34

Quality Assurance $\quad 35$

Acknowledgements 35

References $\quad 36$

$\begin{array}{ll}\text { Appendices } & 37\end{array}$

Appendix A. PVA analytical procedure. 37

Appendix B. Batch distribution coefficient determination 39

Appendix C. Kinetics of PVA oxidation with $\mathrm{H}_{2} \mathrm{O}_{2} / \mathrm{UV}$. 40

Appendix D. Compatibility of PVA with Tank Farm WAC. 43 


\subsection{INTRODUCTION}

Cellulose-based mop heads, wipes and disposable personal protection clothing are currently used as "clean up" products at the Savannah River Site (SRS). These conventional cleaning materials are used in the Canyons and B-line operations for picking up radioactive spills and mixed waste as well as in general decontamination operations. Cellulose and other polymer-based materials, which can not be laundered or incinerated due to high radioactive contamination, organic constituents or mixed waste characteristics are disposed in dry active waste streams (LLW and TRU waste streams) as " bulky solid waste. Increasing cost of final disposal of these types of solid waste makes it necessary to investigate new ways of decreasing radioactive waste treatment and disposal cost.

Polyvinyl alcohol (PVA) fabric is a white woven material, which is currently being evaluated by Solid Waste for use as a substitute for conventional cellulose disposal materials currently used at the Savannah River Site. PVA is a synthetic polymer produced by alkali or acidic hydrolysis of polyvinyl acetate. Molecular weight $(7,000$ $186,000)$ and percent hydrolysis govern the physical properties of PVA, such as solubility in hot water. PVA produced from the hydrolysis of polyvinyl acetate, with 88-98 \% hydrolysis, dissolves most rapidly in cold and hot water (US patents 5,181,966; $5,507,837$ and 5,181,967). Items made from this grade of PVA, especially those without coloring pigments can dissolve in hot water at approximately $90-100{ }^{\circ} \mathrm{C}$. The resulting organic PVA solution, without chemical modification to simpler organic molecules, is not compatible with SRS liquid waste processing facilities like the Tank Farms.

Data from this study will serve as part of the technical basis for accepting PVA waste in SRS Tank Farms and other down stream processes like the Effluent Treatment Facility (ETF). The data will also be useful in the modification of Orex $\otimes$ commercial process (Orex ${ }^{\circledR}$ process is currently used in the solubilizing of PVA) to accommodate PVA chemical degradation features or in the design of an entirely different equipment unit to simultaneously handle solubilizing and chemical degradation of PVA. The data will also be useful for pilot plant testing of such new equipment to treat radioactive laden PVA by oxidation, $\mathrm{pH}$ adjustments and decomposition of excess hydrogen peroxide.

The goals of this PVA study are to:

- Identify and evaluate appropriate PVA oxidative mineralization technique

- Provide both qualitative and quantitative measure of extent of oxidative mineralization of PVA and identify possible oxidation products, if possible.

- Perform evaporation fate tests for neat and mineralized PVA

- Determine potential for PVA and by-product precipitation and/or carryover of radionuclides in Tank Farm environment, i.e. - chemical interference with Tank Farm process chemistry. Interference of PVA/oxidation products with Tank Farm principal ion exchange resins for cesium-137 (Crystalline silicotitanate, tetraphenyl borate), strontium-90 and plutonium (monosodium titanate) removal will be evaluated. The extent of interference will be based on changes in magnitude of batch distribution coefficient $\left(\mathrm{K}_{\mathrm{d}}\right)$ and decontamination factors, $\mathrm{D}_{\mathrm{f}}$. 


\subsection{EXPERIMENTAL}

\subsection{Approach}

PVA was oxidized using potassium permanganate (solid crystals, acidified solutions), and hydrogen peroxide (with and without ultrasonic and ultraviolet treatment). Colorimetric quantification technique (at $670 \eta \mathrm{m}$ ) was used to measure the extent of PVA oxidation, that is, amount of PVA left in solution during and after oxidation.

Both "neat" PVA (unadulterated) solution and resulting oxidized PVA solutions $(<90 \%$ oxidation) were mixed with Tank Farm simulant at room temperature and at temperatures greater than $100^{\circ} \mathrm{C}$ (evaporated) to characterize the mixture for precipitation, skin formation, reverse PVA phase change, and side reaction products, if any. The viscosity and $\mathrm{pH}$ of neat PVA and oxidized PVA solutions were also determined for comparison.

The chemical identity of the principal degradation products of PVA in both potassium permanganate and hydrogen peroxide were evaluated by ion chromatography. The effect of oxidized PVA solutions on the ion exchange treatment process for the uptake of radionuclides (CS-137, Sr-90 and Pu-239) from Tank Farm waste was evaluated with two ion exchange materials and one precipitation agent: CST and TPB for cesium removal, and MST for strontium-90 and plutonium up take.

\section{Apparatus, Chemicals and Materials.}

The experimental apparatus for the oxidation, quantification and measurement of rheological properties of oxidized $\mathrm{PVA}^{\#}$ solutions included the following: ultrasonic disrupter, UV-VIS spectrophotometer, mercury UV lamps (254, 302 and $366 \mathrm{~nm})$, forced-piston viscometer, $\mathrm{pH}$ meter, orbital shaker, ion chromatography technique and evaporation set up. A photo of the $\mathrm{H}_{2} \mathrm{O}_{2} / \mathrm{UV} /$ sonication oxidation set up is shown in Figures 17, 18 and 19. It consists of a multi-wavelength mercury UV lamp (254,302 and $366 \eta \mathrm{m})$ from Draggers, suspended about $10 \mathrm{~mm}$ above pyrex ${ }^{\circledR}$ glass petri-dishes and 150 -mL Teflon ${ }^{\circledR}$ beaker reaction vessels. The sonication device is a $20 \mathrm{kHz}$ ultrasonic generator. See Appendix $\mathrm{C}$ for details.

The principal chemicals and reagents included potassium permanganate, $50 \%$ hydrogen peroxide (Hach), PVA (5\%), concentrated nitric acid, boric acid, iodine, potassium iodide, milli-Q water, crystalline silicotitanate ${ }^{*}$ (CST), monosodium titanate ${ }^{* *}$ (MST) and teraphenyl borate ${ }^{* * *}$ (TPB).

\footnotetext{
"Polyvinyl Alcohol (PVA) fabric was furnished by Isolyser company Inc. 4320 International Blvd, Norcross, GA 300093, (770-806-9898).

Engineered granular form of Crystalline silicotitante (CST) ion-exchange material developed by Sandia National Laboratory and Texas A\&M University (UOP Ionsive IE-911, (lot \# 999096810002).

"Monosodium Titanate slurry was supplied by Allied Signal Research and Technology Group, 50 East Algonquin Road, Des Plaines, IL.

*** Obtained locally from the Plant.
} 


\subsection{Method}

Preparation of 5\% PVA solution and colorimetric determination of PVA

Five percent PVA solution was prepared by slowly dissolving $50.000 \pm 0.0001$ grams of PVA fabric in about $700 \mathrm{~mL}$ milli-Q (distilled and de-ionized water) water on a hot plate. The temperature of the hot water was maintained between $90-100{ }^{\circ} \mathrm{C}$. After the complete dissolution of the PVA in about $700 \mathrm{~mL}$ of hot water the solution was quantitatively transferred into a $1000-\mathrm{mL}$ volumetric flask and the solution volume brought to mark with milli-Q water. This approach requires continuous stirring of the mixture to prevent the formations of small hydrated PVA balls. These small hydrated balls are not soluble even in hot water. It is, however, easier to prepare 4\% and 3\% PVA solutions, and this helps in preventing the formation of these PVA ball suspensions.

The method for determining percent PVA left in solution after oxidation was adapted from an Air Product company's procedure for determination of PVA concentration in dilute aqueous matrices such as those obtained from the extraction of paper (3). This colorimetric technique is based on the formation of stable PVA green colored complexes with iodine in the presence of boric acid. The absorbance of the sample solution is measured and compared with a calibration curve prepared from the same grade of PVA. The wavelength of maximum absorbance of the iodine/PVA complex was determined to be around $670 \mathrm{\eta m}$ (see below for determination of maximum absorption wavelength for the complex). A Hach DR/300 UV-VIS spectrophotometer, a single beam instrument with a double-pass grating monochromator capable of wavelengths from $325-1000 \eta \mathrm{m}$, was used for the colorimetric quantification of percent PVA in solution. A summary of the adapted procedure is attached as Appendix A.

\section{PVA calibration curve}

For comparison, calibration curves were prepared in two ways: direct preparation of stock solution from PVA fabric and serial dilution of 5\% PVA solution to required stock solution concentration. In the first case a $0.5 \%$ PVA (by weight) solution was quantitatively prepared (stock solution) by dissolving $0.1000 \mathrm{~g}$ of PVA fabric in $20-\mathrm{mL}$ of hot water at $100^{\circ} \mathrm{C}$. $10 \mathrm{~mL}$ of the stock solution was diluted to $1000 \mathrm{~mL}(0.005 \%$ PVA intermediate stock solution) and the calibration standards prepared from this intermediate stock solution. The diluting solution was comprised of iodine and boric acid solutions and milli-Q water (see Appendix A for details). Ten calibration standards were obtained by diluting various aliquot samples of the intermediate stock solution to the 100$\mathrm{mL}$ mark in a $100 \mathrm{~mL}$ volumetric flask. To determine the maximum absorption wavelength for the PVA/iodine/boric acid complex a wavelength scan of the 8-mL standard (standard \# 4 below) was determined from 500-800 $\mathrm{\eta m}$. Results for the wavelength scan and absorption profile are summarized in Tables 1, 2 and Figure 1 below. The PVA/iodine complex has one principal absorption peak maxima centered at about 670 ๆm (Figure 1).

Based on this information ( $\lambda \max$ at $670 \eta \mathrm{m}$ ) the absorbance of each calibration standard and the determination of the percent amount of PVA in solutions were determined at 670 $\eta \mathrm{m}$. Figure 2 shows the concentration (\%PVA) versus absorbance profile for PVA 
dissolved in milli-Q water. The calibration equation for the \%PVA versus absorbance profile is linear. Where

$$
\mathrm{Y}(\% \mathrm{PVA})=0.0022 \mathrm{X}(\text { absorbance })-0.000003
$$

\begin{tabular}{|l|l|l|l|}
\hline Standard $\#$ & mL of intermediate stock per 100 $\mathbf{~ L L}$ & \%PVA in standard & Average absorbance \\
\hline $\mathbf{0}$ & $\mathbf{0 . 0}$ (iodine and boric acid in water) & $\mathbf{0}$ & $\mathbf{0 . 0}$ \\
\hline 1 & 1.0 & 0.00005 & $0.032 \pm 0.006$ \\
\hline 2 & 3 & 0.00015 & $0.087 \pm 0.010$ \\
\hline 3 & 5 & 0.00025 & $0.138 \pm 0.006$ \\
\hline 4 & 8 & 0.00040 & $0.193 \pm 0.010$ \\
\hline 5 & 10 & 0.00050 & $0.238 \pm 0.014$ \\
\hline 6 & 15 & 0.00075 & $0.365 \pm 0.008$ \\
\hline 7 & 20 & 0.00100 & $0.486 \pm 0.012$ \\
\hline 8 & 25 & 0.00125 & $0.596 \pm 0.010$ \\
\hline 9 & 30 & 0.00150 & $0.680 \pm 0.007$ \\
\hline
\end{tabular}

Table 1 Calibration and absorbance data for colorimetric quantification of PVA

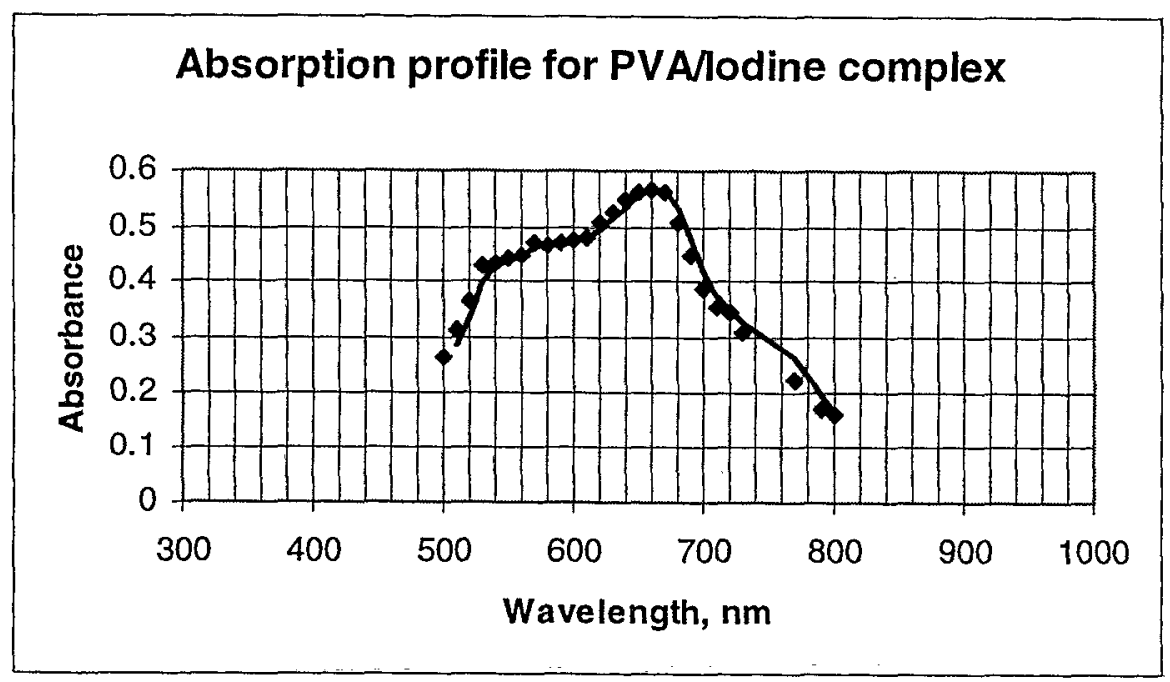

Figure 1. Absorption profile for PVA/Iodine/Boric acid complex.

Maximum absorption peak $(\lambda \max )$ is around $670 \mathrm{\eta m}$. 


\begin{tabular}{|c|c|}
\hline Wavelength, $\eta \mathrm{m}$ ) & Absorbance \\
\hline 500 & 0.264 \\
\hline 510 & 0.312 \\
\hline 520 & 0.365 \\
\hline 530 & 0.428 \\
\hline 540 & 0.434 \\
\hline 550 & 0.444 \\
\hline 560 & 0.45 \\
\hline 570 & 0.473 \\
\hline 580 & 0.466 \\
\hline 590 & 0.469 \\
\hline 600 & 0.476 \\
\hline 610 & 0.482 \\
\hline 620 & 0.506 \\
\hline 630 & 0.525 \\
\hline 640 & 0.549 \\
\hline 650 & 0.564 \\
\hline 660 & 0.568 \\
\hline 670 & 0.564 \\
\hline 680 & 0.508 \\
\hline 690 & 0.449 \\
\hline 700 & 0.39 \\
\hline 710 & 0.354 \\
\hline 720 & 0.348 \\
\hline 730 & 0.309 \\
\hline 770 & 0.221 \\
\hline 790 & 0.171 \\
\hline 800 & 0.162 \\
\hline
\end{tabular}

Table 2. Absorbance profile data for PVA/Iodine/Boric acid complex.

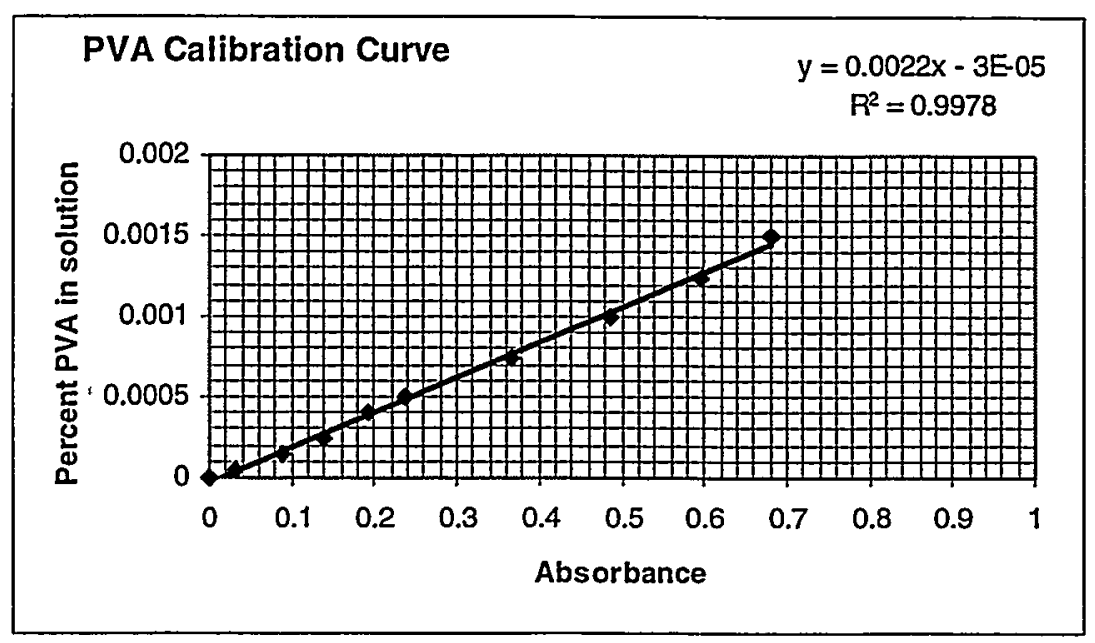

Figure 2. PVA calibration curve based on Iodine/boric acid/PVA complex absorbance at $670 \eta \mathrm{m}$. 
When the standards were based on straight serial dilution of stock 5\%PVA solution the equation obtained relating the percent PVA to the absorbance was:

$\mathrm{Y}(\% \mathrm{PVA})=0.0021 \mathrm{X}$ (absorbance $)$

The two calibration equations are almost identical and were reproducible.

\subsection{PVA oxidation with potassium permanganate.}

\subsection{PVA oxidation with solid permanganate crystals.}

The use of non-aqueous based permanganate crystals will minimize final waste volume.

Procedure

Oxidation of PVA with potassium permanganate was carried out with known amounts of potassium permanganate crystals directly added to polyethylene vials containing $10-\mathrm{ml}$ portions of PVA $(5 \%)$ solution at room temperature. The vials were put into an orbital shaker for agitation to ensure uniform mixing and dissolution of the oxidizing crystals. After mixing of the PVA with the oxidizing crystals the oxidation was almost instantaneous. Ten minutes after mixing the content of each vial was analyzed for percent PVA left in solution.

\section{$\underline{\text { Results }}$}

Table 3 and Figure 3 below contain data from a typical oxidation sequence of PVA with crystals of potassium permanganate. For a better than $90 \%$ oxidation of PVA 0.24 grams of solid crystal of potassium permanganate per $10 \mathrm{ml}$ portion of PVA (5\%) was needed. Using this amount of solid potassium permanganate ensured there was no precipitation of black manganese particles. This translates to 24 grams of solid permanganate per liter of $5 \%$ PVA waste solution $\left(\approx 91\right.$ grams of $\mathrm{KMnO}_{4}$ per gallon of 5\% PVA waste). A higher concentration of potassium permanganate than $24 \mathrm{gm} /$ liter yielded almost a $100 \%$ oxidation of PVA. However, there was precipitation of black manganese dioxide and the resulting mixture forms a jelly-like paste, which may not be pumpable. After 24 hours on bench top, it was noticed that all the samples in vials containing greater than or equal to 0.25 grams of potassium permanganate per $10-\mathrm{ml}$ portion of oxidized 5\% PVA had turned into a solid paste. The black solid pastes are attributed to precipitates of black manganese dioxide. The advantage of using solid potassium permanganate solid crystals includes minimization of final waste volume after oxidation of PVA.

In the oxidation of PVA a better than $90 \%$ degradation is considered an acceptable extent of mineralization of PVA, because the remaining PVA in solution is denatured up to the point where it does not posses neat PVA solution characteristics (interference with Tank Farm chemistry is minimal). This $90 \%$ benchmark was selected by mixing different levels of oxidized PVA with Tank Farm simulant and observing for reverse dissolution or precipitation of PVA. 


\begin{tabular}{|l|l|l|l|}
\hline $\begin{array}{l}\mathrm{Wt} \text { Of } \mathrm{KMnO}_{4}, \mathrm{~g} \\
\text { Per } 10 \mathrm{~mL} \mathrm{PVA}\end{array}$ & $\begin{array}{l}\text { \% PVA in solution } \\
\text { after oxidation }\end{array}$ & $\begin{array}{l}\text { Extent of } \\
\text { oxidation, \% }\end{array}$ & Comments \\
\hline 0.0 & 5 & 0.0 & \\
\hline 0.15 & 1.12 & 77.68 & $\begin{array}{l}\text { No precipitation. of } \mathrm{MnO}_{2} \\
\text { or formation of jelly mixture }\end{array}$ \\
\hline 0.22 & 0.78 & 84.50 & $\begin{array}{l}\text { No precipitation. of } \mathrm{MnO}_{2} \\
\text { or formation of jelly mixture }\end{array}$ \\
\hline 0.25 & 0.35 & 92.94 & $\begin{array}{l}\text { Precipitate. and jell } \\
\text { formation overnight }\end{array}$ \\
\hline 0.28 & 0.21 & 95.76 & $\begin{array}{l}\text { Precipitate. and jell } \\
\text { formation overnight. }\end{array}$ \\
\hline 0.33 & 0.18 & 96.50 & $\begin{array}{l}\text { Precipitate and jell } \\
\text { formation overnight. }\end{array}$ \\
\hline & & & $\begin{array}{l}\text { Precipitate and jell } \\
\text { formation instantly }\end{array}$ \\
\hline 0.4 & 0.12 & 97.78 &
\end{tabular}

Table 3. Oxidation of PVA with solid potassium permanganate. About $0.24 \mathrm{gm}$ of solid potassium permanganate per $10 \mathrm{~mL}$ of $5 \%$ PVA is required to obtain a better than $90 \%$ oxidation of PVA without precipitation of manganese dioxide.

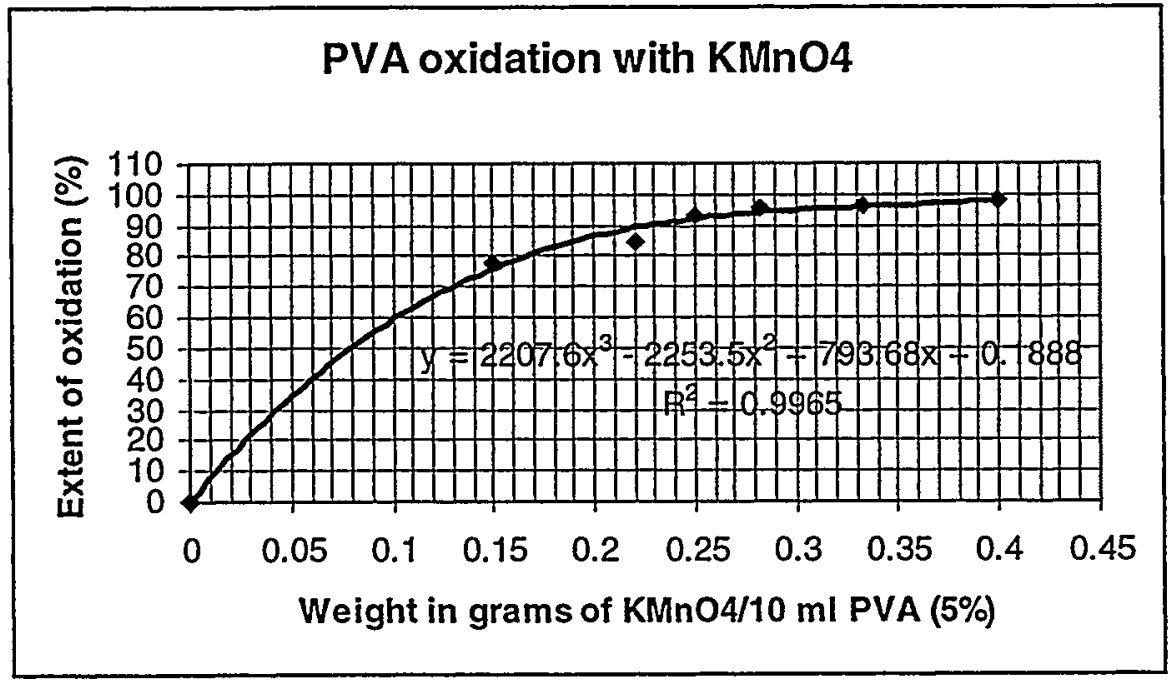

Figure 3. PVA oxidation with solid potassium permanganate crystals. About twenty four grams of $\mathrm{KMnO}_{4}$ crystals are required per liter of 5\% PVA in order to obtain a better than $90 \%$ oxidation of PVA. The resulting oxidized PVA waste solution does not contain precipitates of black manganese dioxide. 


\subsection{PVA oxidation with acidified potassium permanganate}

Procedure

Acidified 0.35 molar potassium permanganate solution was used for the oxidation of PVA (5-mL conc. $\mathrm{HNO}_{3}$ per liter of $0.35 \mathrm{M}$ solution of $\mathrm{KMnO}_{4}$ ). Varying volumes of the permanganate solution $\left(0.5-5 \mathrm{ml}\right.$ of $\left.3.5 \mathrm{M} \mathrm{KmnO}_{4}\right)$ were mixed with $10-\mathrm{ml}$ portions of 5\% PVA solutions, and after shaking for 10 minutes the amount of PVA left in each solution was determined colorimetrically as earlier described.

$\underline{\text { Results }}$

The oxidation time needed for a better than $90 \%$ mineralization of PVA was relatively shorter for acidified permanganate solution in comparison with unacidified or solid permanganate oxidation of PVA. In addition, there were relatively no manganese dioxide $\left(\mathrm{MnO}_{2}\right)$ precipitates. Smaller volumes of acidified $\mathrm{KMnO} 4$ solutions $(0.35 \mathrm{M})$ were required for a better than $90 \%$ oxidation of PVA (5\%) and oxidized PVA solutions were clear and colorless due to the absence of $\mathrm{MnO}_{2}$ precipitates. To obtain a better than $97 \%$ oxidation of PVA (5\%) only about 2-mL portions of acidified $\mathrm{KMnO}_{4}(0.35 \mathrm{M})$ per 10$\mathrm{ml}$ of 5\%PVA were required (Figure 4). In other words, acidified PVA solutions require less potassium permanganate for complete minerlization $\left(11.5 \mathrm{~g} \mathrm{KMnO}_{4} / \mathrm{L}\right.$ or $43.5 \mathrm{~g}$ $\mathrm{KMnO}_{4}$ /gallon).

Oxidized PVA samples from acidified permanganate oxidation with $\mathrm{pH}$ values less than 2 were put into small glass vials and the $\mathrm{pH}$ of the samples adjusted with 1.0 molar solution of sodium hydroxide to $\mathrm{pH} 12$. After the $\mathrm{pH}$ adjustment black precipitates of $\mathrm{MnO}_{2}$ was observed through out the sample matrix.

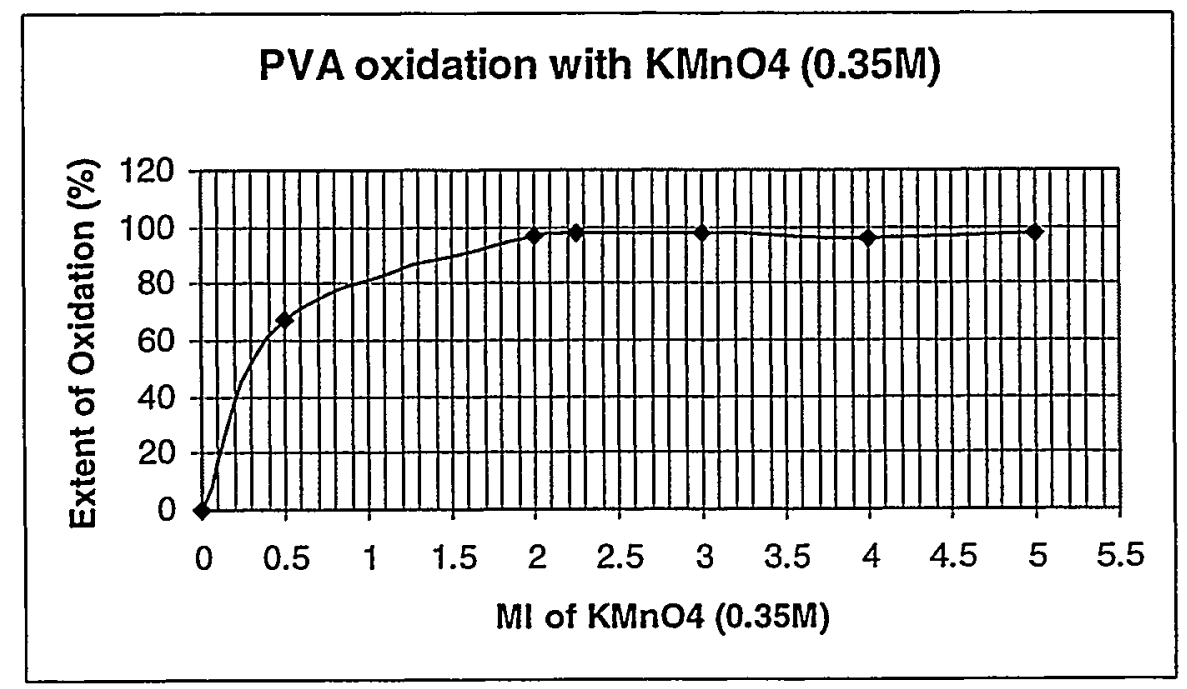

Figure 4---Oxidation of 5\% PVA solution with $0.35 \mathrm{M}$ solution of $\mathrm{KMnO}_{4}$. Approximately $2 \mathrm{~mL}$ of acidified $\mathrm{KMnO}_{4}(0.35 \mathrm{M})$ per $10 \mathrm{~mL}$ of PVA $(5 \%)$ is required to obtain a better than $97 \%$ oxidation of PVA $(5 \%)$. 
Based on above information (2-mL of acidified $\mathrm{KMnO}_{4}(0.35 \mathrm{M})$ per 10-ml of 5\%PVA was required for a better than $97 \%$ oxidation of PVA.) one can construct a table showing the volume of acidified $\mathrm{KMnO}_{4}(0.35 \mathrm{M})$ solution required to obtain about $97 \%$ PVA oxidation for any given percent PVA in solution. A typical experimental result is summarized in Table 4 and Figure 5 below. All five samples of PVA solution, with different percent PVA compositions, showed an average of $97 \pm 1 \%$ extent of PVA (5\%) oxidation with their respective calculated amounts of acidified $\mathrm{KMnO}_{4}(0.35 \mathrm{M})$.

From the linear equation in Figure 5, grams of potassium permanganate per $\mathrm{mL}$ of a given percent PVA solution (acidified) required for a better than $97 \%$ oxidation of PVA can be calculated.

$\mathrm{Y}\left(\mathrm{g} \mathrm{KMnO}_{4} / \mathrm{mL} \mathrm{PVA}\right)=0.0018(\% \mathrm{PVA})+0.0002$.

\begin{tabular}{|l|l|l|l|}
\hline $\begin{array}{l}\text { Initial [PVA], } \\
\%\end{array}$ & $\begin{array}{l}\mathrm{KMnO}_{4}(0.35 \mathrm{M}) \text { Volume } \\
\text { required for }>\mathbf{9 7} \% \\
\text { oxidation of PVA, }\end{array}$ & $\begin{array}{l}\text { Extent of oxidation } \\
\text { obtained experimen- } \\
\text { tally }(\%)\end{array}$ & $\begin{array}{l}\mathrm{KMnO}_{\mathbf{4}} \text { per } \mathrm{mL} \text { of } \\
\text { solution } \\
(\mathrm{g})\end{array}$ \\
\hline 5 & 2.0 & 97.6 & 0.0092 \\
\hline 4 & 1.6 & 97.8 & 0.0073 \\
\hline 3 & 1.2 & 97.4 & 0.0059 \\
\hline 2.5 & 1.0 & 96.8 & 0.0050 \\
\hline 1.5 & 0.6 & 95.7 & 0.0031 \\
\hline
\end{tabular}

Table 4. Summary of oxidation data for PVA oxidation with acidified $\mathrm{KMnO}_{4}$ Extent of PVA oxidation is about $97 \%$.

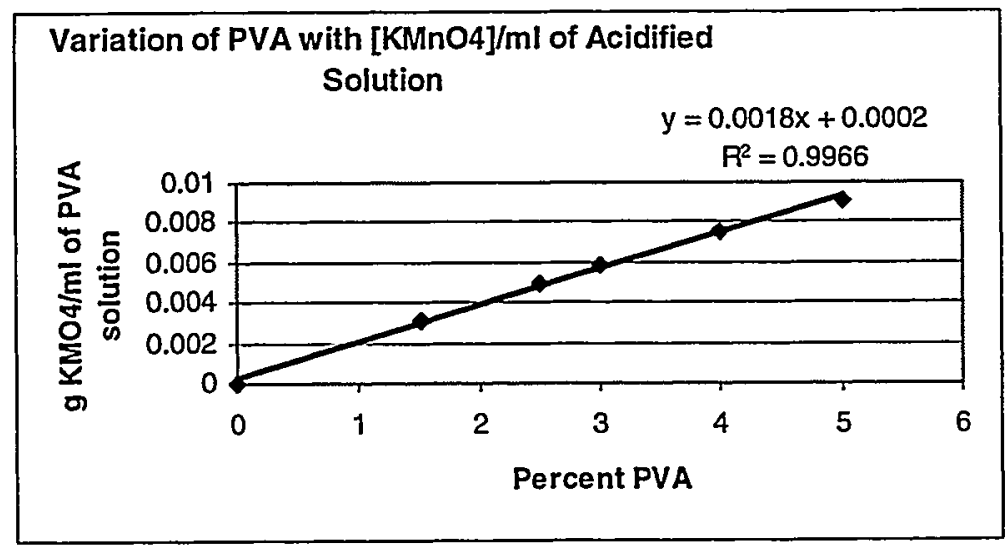

Figure 5. Plot of percent PVA versus gram of $\mathrm{KMnO}_{4}$ per $\mathrm{mL}$ of acidified of PVA. The amount of $\mathrm{KMnO}_{4}$, which is required for the complete minerlization of any given percent amount of PVA, can be calculated.

Oxidation of PVA with acidified permanganate coupled with ultrasonic treatment (sonication or sonochemical treatment) did not enhance the process significantly. 


\subsection{Photochemical and sonochemical oxidation of PVA in hydrogen peroxide.}

The oxidation of a mixture of 5\% PVA solution with hydrogen peroxide at room temperature required about 10 to 14 days aging to obtain a better than $90 \%$ mineralization of 5\%PVA solution. This was the case even when the PVA and hydrogen peroxide were in a 1:1 ratio by volume. To enhance the oxidation rate of PVA in the presence of hydrogen peroxide, sonochemical (ultrasonic irradiation) and UV photochemical (ultraviolet light irradiation) techniques were employed. UV-based dissociation of $\mathrm{H}_{2} \mathrm{O}_{2}$ produces hydroxyl and other superperoxides. These peroxides are responsible for the eventual mineralization of the PVA in solution. Three principal UV wavelengths (254, 302 and $366 \mathrm{\eta m}$ ) were evaluated for the photochemical oxidation of PVA in the presence of $\mathrm{H}_{2} \mathrm{O}_{2}$. The reaction rates for the oxidation of PVA in the presence of $\mathrm{H}_{2} \mathrm{O}_{2}$ was evaluated first without sonochemical treatment of mixture of hydrogen peroxide and PVA. Combined sonochemical and photochemical treatments at various UVwavelengths followed this. No measurable PVA oxidation changes were observed with just treating 5\% PVA solutions with ultrasonic waves at 90 Watts for five minutes.

There was no appreciable improvement on reaction rate over PVA oxidation with only $\mathrm{H}_{2} \mathrm{O}_{2}$ when photochemical treatment at $254 \eta \mathrm{m}$ was carried out in the presence of $\mathrm{H}_{2} \mathrm{O}_{2}$. Faster oxidation rates for the mineralization of PVA with UV in the presence of $\mathrm{H}_{2} \mathrm{O}_{2}$ were attained only with 302 and $366 \eta \mathrm{m}$ UV treatments.

\section{Procedure}

Basically three types of PVA oxidation runs were carried out: Oxidation with just PVA in hydrogen peroxide, oxidation of PVA/hydrogen peroxide with ultraviolet irradiation and PVA/hydrogen peroxide oxidation with ultrasonic and ultraviolet treatment.

In the first type of oxidation runs, various proportions of PVA and $\mathrm{H}_{2} \mathrm{O}_{2}\left(5\right.$ to $33 \% \mathrm{H}_{2} \mathrm{O}_{2}$ relative to total volume of PVA to be mineralized) were mixed in $150-\mathrm{mL}$ polyethylene bottles at room temperature. After every 24 hours samples were collected from each bottle and the amount of PVA left in solution was analyzed. In the second type of runs, oxidation of $\mathrm{PVA} / \mathrm{H}_{2} \mathrm{O}_{2}$ coupled with $\mathrm{UV}$ treatment at a given wavelength, say $366 \eta \mathrm{m}$, was carried out in petri-dishes with mixtures as in above $\mathrm{H}_{2} \mathrm{O}_{2} /$ PVA proportion and range (see Figure 17). In the third type of oxidation runs, the $\mathrm{PVA} / \mathrm{H}_{2} \mathrm{O}_{2}$ sample mixtures (5 to $33 \% \mathrm{H}_{2} \mathrm{O}_{2}$ ) were treated with ultraviolet and ultrasonic radiation. Each sample mixture was put into $150-\mathrm{mL}$ Teflon ${ }^{\circledR}$ or Pyrex ${ }^{\circledR}$ glass beaker and sonicated (ultrasonic energy maintained at $4.6 \mathrm{Watts} / \mathrm{cm}^{2}$ ) for three minutes initially and then exposed to UV light at $366 \eta \mathrm{m}$. The samples could also be sonicated continuously at a given time interval while it was being treated with UV light. For run types two and three above, at intervals of 2030 minutes $0.1 \mathrm{~mL}$ samples were collected and quantified for percent PVA left in solution (measure of extent of oxidation). This was carried on until a better than $90 \%$ conversion of PVA was attained. Figures 17, 18 and 19 show typical experimental arrangements. 


\section{$\underline{\text { Results }}$}

4.10 PVA oxidation with $\mathrm{H}_{2} \mathrm{O}_{2}$ only

As earlier mentioned, it took an average of about 12 days to obtain a greater than $90 \%$ mineralization of PVA with hydrogen peroxide oxidation only. The oxidation of PVA with hydrogen peroxide with sonochemical treatment showed a small increase in reaction rate. The average time required for a better than $90 \%$ oxidation of PVA was reduced by $24 \%$.

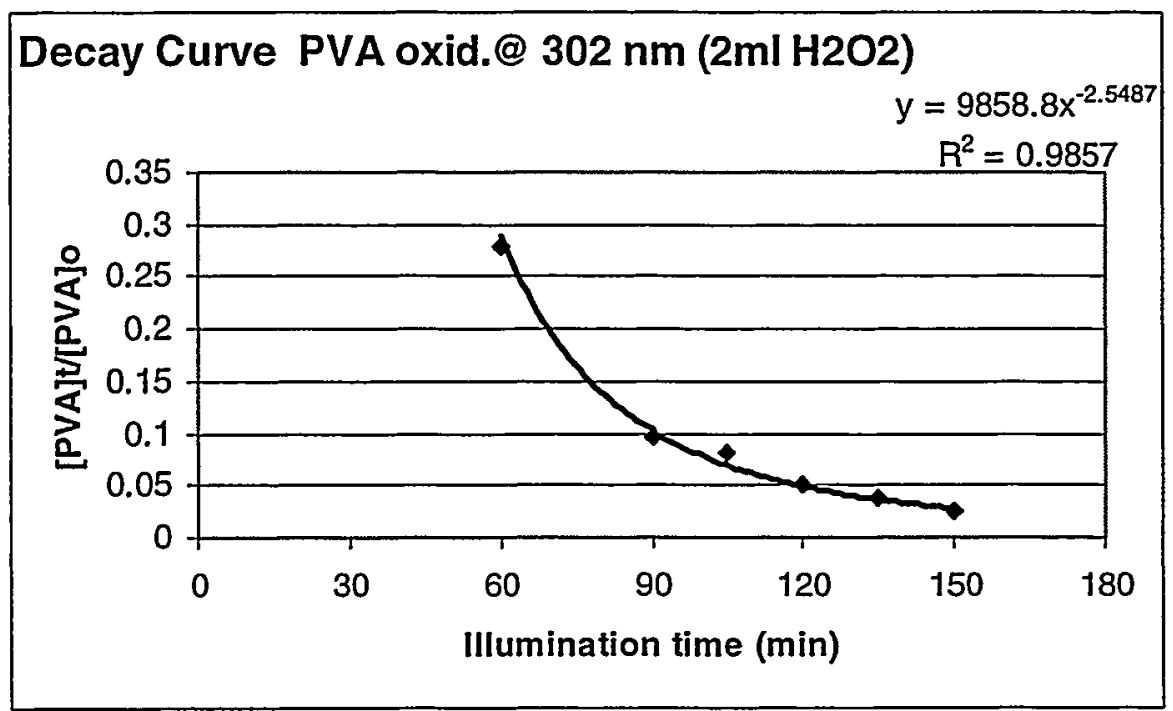

Figure 6. A typical decay curve for PVA oxidation with $\mathrm{H}_{2} \mathrm{O}_{2} / \mathrm{UV}$ at $302 \mathrm{~nm}$ with ultrasonic treatment.

PVA oxidation: Decay curve with and without sonication

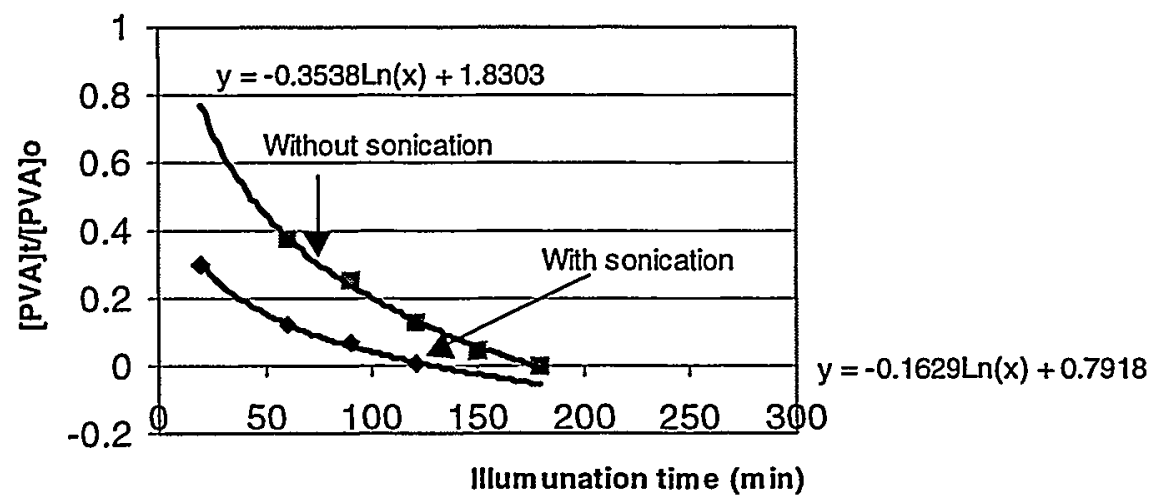

Figure 7. A typical decay curve for PVA oxidation in $\mathrm{H}_{2} \mathrm{O}_{2}$ with and without sonochemical treatment. There is a faster PVA decay with sonication. 
4.20 Photochemical oxidation of $\mathrm{H}_{2} \mathrm{O}_{2}$ /PVA at $366 \mathrm{~nm}$ with and without initial sonochemical treatment.

With PVA oxidation using Photochemical and sonochemical treatment in the presence of hydrogen peroxide the average time required (initial sonication for three minutes only) to attain a greater than $90 \%$ oxidation (T-90) of PVA was reduced from days to hours.

Figures 6 and 7 show typical decay curves and Figure 8 is a typical reaction rate plot for the oxidation of PVA with $\mathrm{H}_{2} \mathrm{O}_{2}$ coupled with UV light at $366 \eta \mathrm{m}$. Here [PVA $]_{\mathrm{t}}$ and $[\mathrm{PVA}]_{0}$ are, respectively, PVA percent concentrations after oxidation time, $t$, and initial PVA concentration. Figure 9 shows an overlay plot for data obtained with PVA oxidation at $366 \eta \mathrm{m}$, with and without sonication, in the presence of $\mathrm{H}_{2} \mathrm{O}_{2}$ per equation 10, Appendix C. Slopes in Figure 9 are, respectively, $0.0219 \mathrm{~min}^{-1}$ for oxidation with initial sonication for three minutes before exposure to $U V$ at $366 \mathrm{\eta m}$ and $0.0176 \mathrm{~min}^{-1}$ without sonication. This decay rate of sonicated $\mathrm{PVA} / \mathrm{H}_{2} \mathrm{O}_{2}$ samples is also faster as reflected in the decay curves in Figure 7. Rate of PVA oxidation in the presence of hydrogen peroxide and UV (366 $\eta \mathrm{m})$ coupled with sonication is therefore faster.

\subsection{Continuous ultrasonic and UV treatment of $\mathrm{H}_{2} \mathrm{O}_{2} /$ PVA mixtures at $366 \mathrm{~nm}$}

\section{Procedure}

In continuous sonicated and UV treated runs, samples under UV lights were sonicated for three minutes at intervals of 30 minutes, with ultrasonic energy maintained at 90 Watts. (Care must be exercised in the use of $100-\mathrm{mL}$ Pyrex ${ }^{\circledR}$ beaker as sample container for the sonication. The beaker must contain enough sample, at least $50 \mathrm{~mL}$, to prevent the shattering of the beaker due to ultrasonic energy.) At the end of every 20 minutes aliquot samples $(0.1 \mathrm{~mL})$ were collected for analysis and determination of percent of PVA left in solution. This was carried out until a better than $90 \%$ oxidation was attained. With this continuous sonication/UV treatment of PVA $/ \mathrm{H}_{2} \mathrm{O}_{2}$ mixtures the entire reaction time, the T-90 time, was further reduced from hours to minutes for both oxidation at 366 and 302 $\eta \mathrm{m}$ (see ahead).

\section{Results}

Table 5 is a summary of PVA oxidation data with $\mathrm{UV} / \mathrm{H}_{2} \mathrm{O}_{2}$ coupled with ultrasonic treatment for various proportions of $\mathrm{H}_{2} \mathrm{O}_{2}$ in PVA (5\%). This table also contains the calculated average reaction rate constants (equation 6 Appendix $\mathrm{C}$ ), the average UV illumination time (T-90) needed to obtain a better than $90 \%$ oxidation of PVA $(5 \%)$ and corresponding proportions of $\mathrm{H}_{2} \mathrm{O}_{2}$ in PVA (5\%). The first part of Table 5 (columns 2 through 5) shows only a single set of data for oxidation without sonication treatment for comparison. Figures $10 \mathrm{a}$ and $10 \mathrm{~b}$ are, respectively, plots of percent hydrogen peroxide versus T-90 illumination time and reaction rate constant versus percent hydrogen peroxide for UV and ultrasonic treatment of $\mathrm{PVA} / \mathrm{H}_{2} \mathrm{O}_{2}$ mixtures. The reaction rate constant shows a continuous increase with increase in volume percent of $\mathrm{H}_{2} \mathrm{O}_{2}$ in the reaction mixture. The T-90 time curve shows an exponential decrease in time required for oxidation of PVA with increase in percent by volume of $\mathrm{H}_{2} \mathrm{O}_{2}$. 
Based on Figures 10a and 10b, for any chosen percent hydrogen peroxide used in the oxidation of 5\% PVA the corresponding reaction rate constant and time required for a better than $90 \%$ mineralization of PVA can be determined by extrapolation. It is worth noting that parameters obtained from these plots (Figures 10a and 10b) are only valid for oxidation at $366 \eta \mathrm{m}$ with ultrasonic energy at $4.6 \mathrm{Wat} / \mathrm{cm}^{2}$.

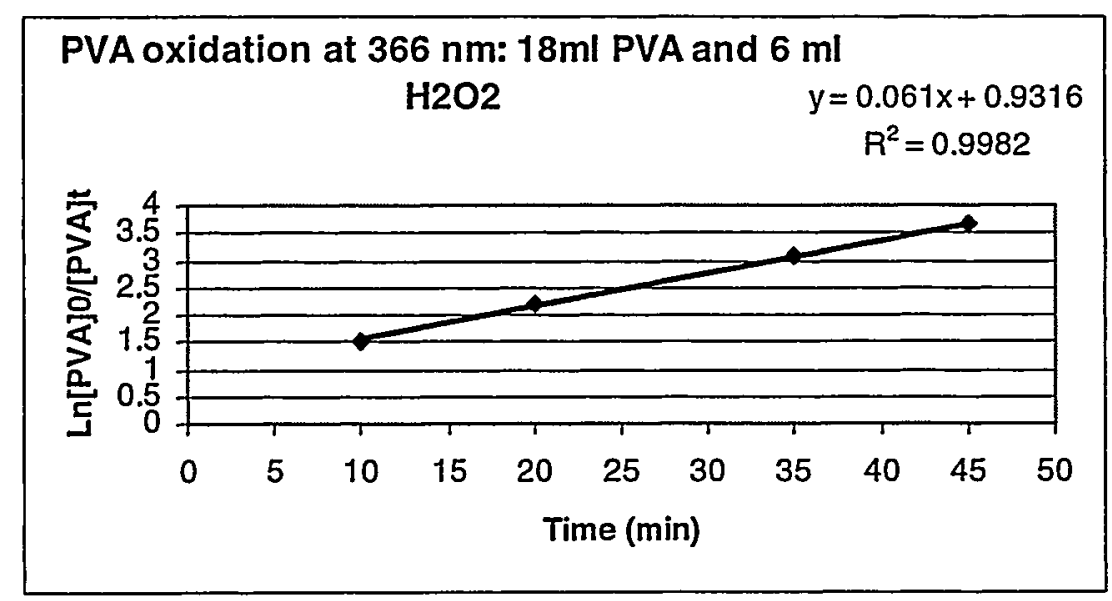

Figure 8. A typical PVA oxidation profile per equation 6, Appendix C.

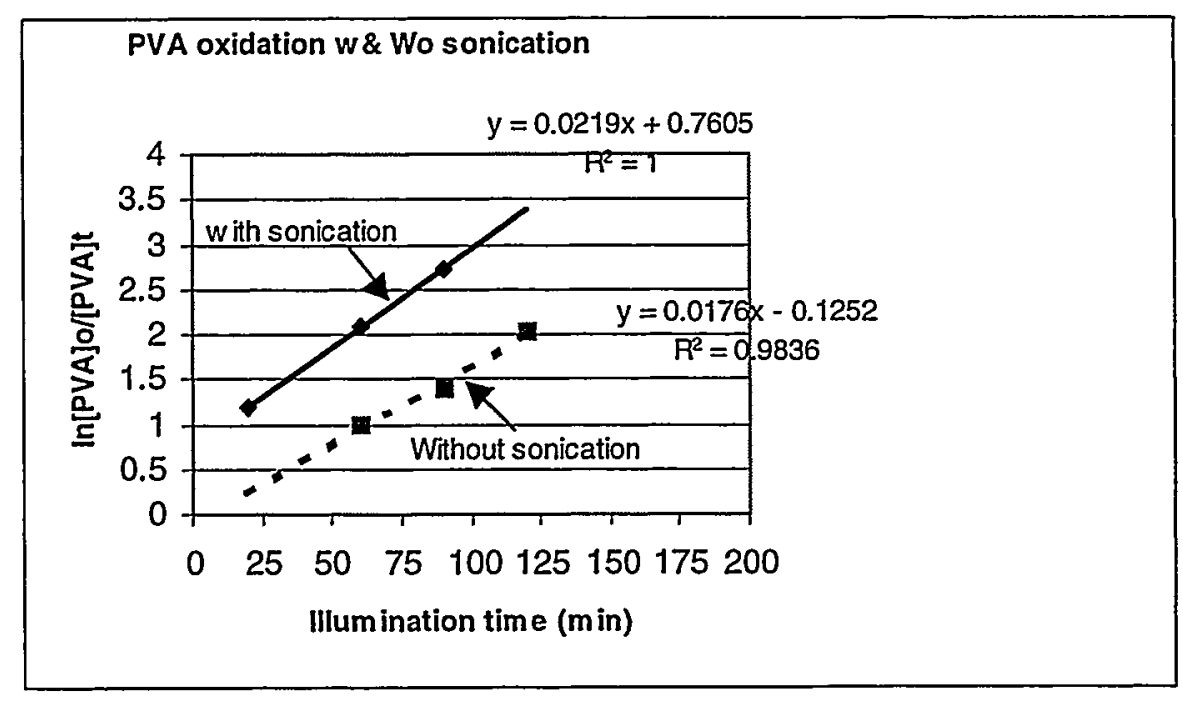

Figure 9. Plots per equation 6 Appendix C. for oxidation with and without ultrasonic treatment. Slopes of the linear plots are equal to reaction rate constants. Ultrasonic treated samples have higher reaction rates constant values. 


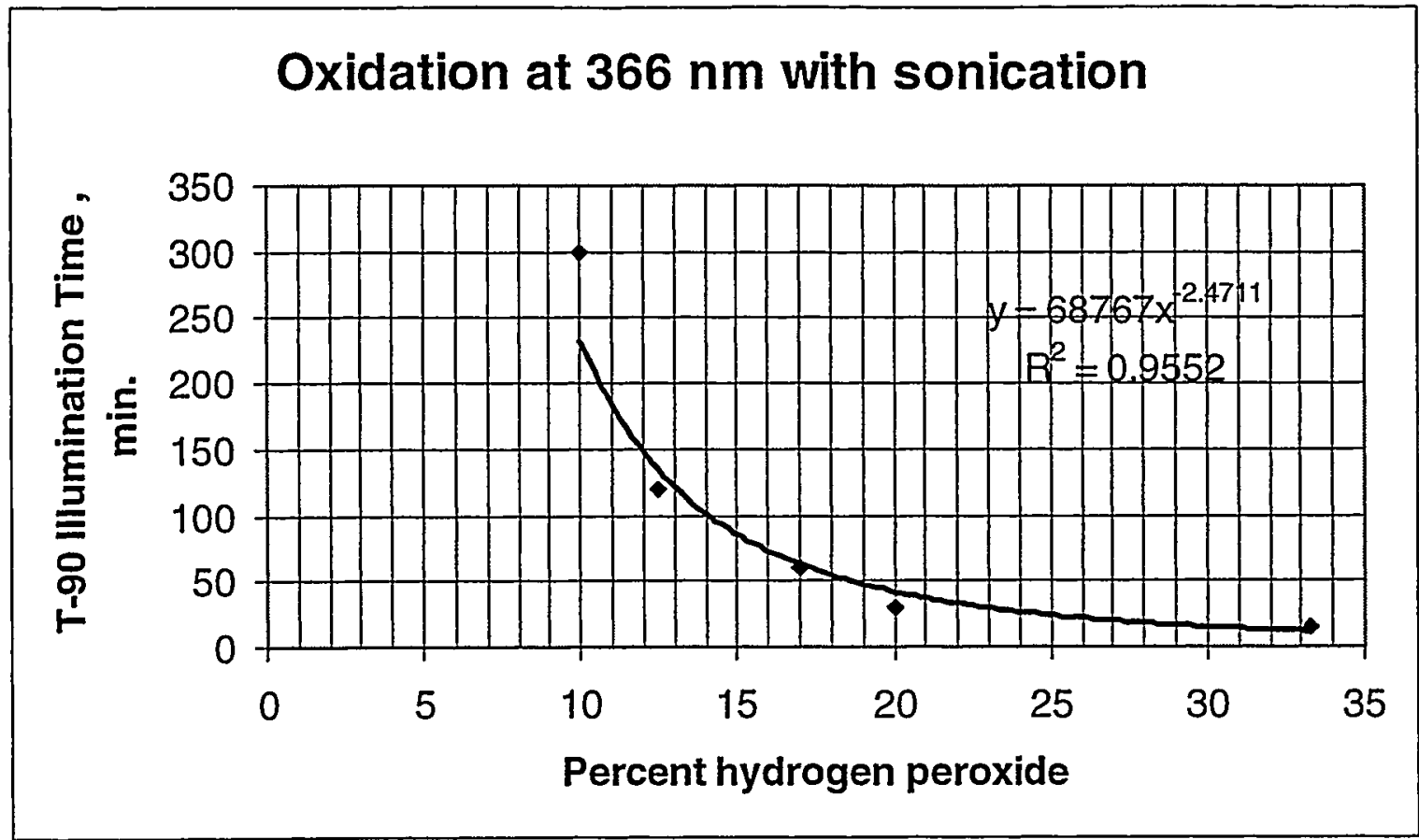

Figure 10a. Variation of illumination time (T-90) with percent hydrogen peroxide at 366 $\eta \mathrm{m}$ with ultrasonic treatment. $\mathrm{T}-90$ is the minimum time required for a better than 90 percent mineralization of 5\% PVA in 50\% aqueous hydrogen peroxide.

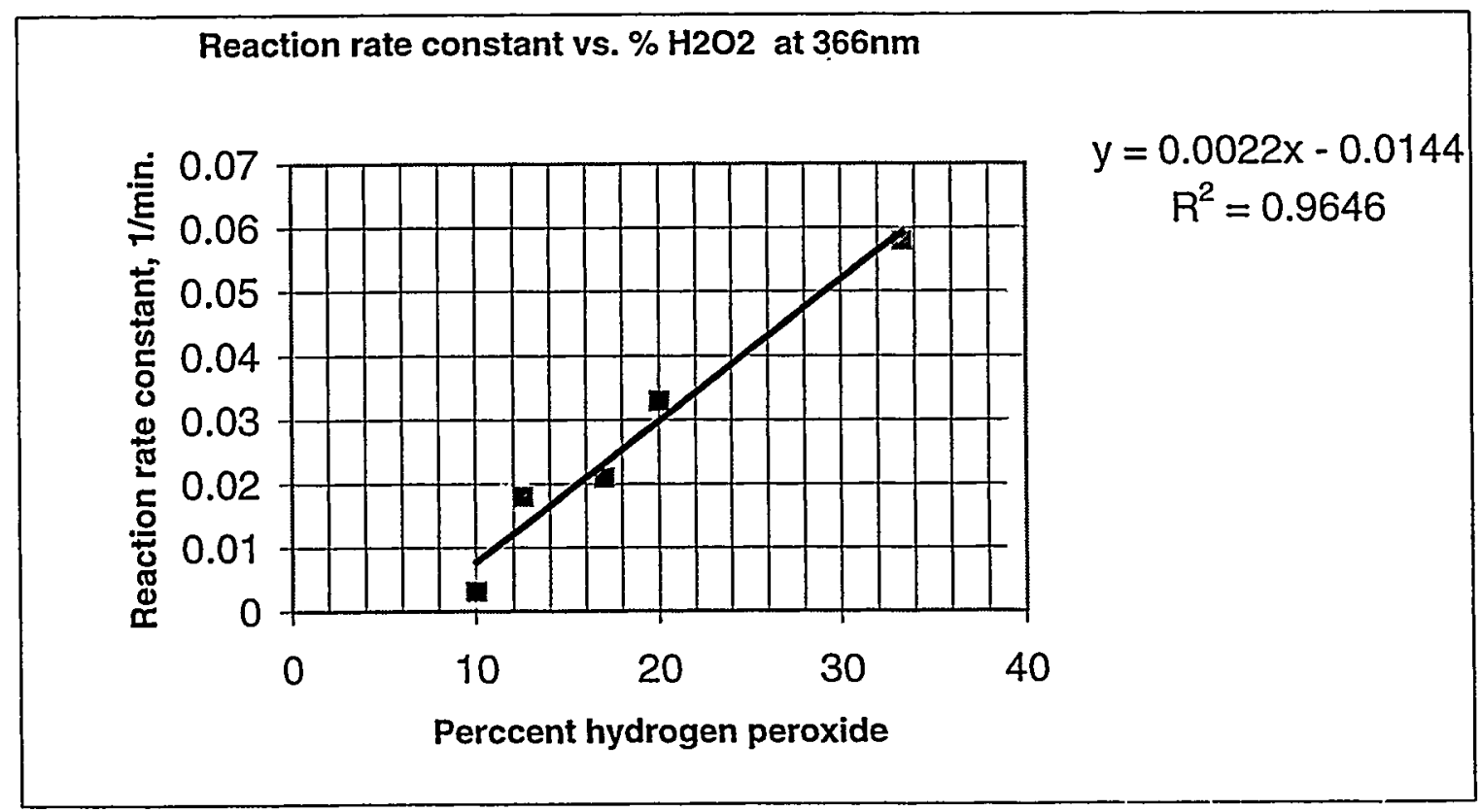

Figure 10b. Changes in reaction rate constant with percent hydrogen peroxide used in oxidative mineralization of 5\% polyvinyl alcohol solution at $366 \mathrm{\eta m}$ (with sonication). 


\begin{tabular}{|l|l|l|l|l|l|l|l|l|}
\hline & \multicolumn{3}{|l|}{ Without Sonication } & \multicolumn{4}{|c|}{ With sonication } \\
\hline$\% \mathrm{H}_{2} \mathrm{O}_{2}$ & $\begin{array}{l}\text { Rate*1000 } \\
\left(\mathrm{min}^{-1}\right)\end{array}$ & $2 \sigma$ & $\begin{array}{l}\mathrm{T}-90 \\
(\mathrm{~min} .)\end{array}$ & $2 \sigma$ & $\begin{array}{l}\text { Rate*1000 } \\
\left(\mathrm{min}^{-1}\right)\end{array}$ & $2 \sigma$ & $\begin{array}{l}\text { T-90 } \\
(\mathbf{m i n} .)\end{array}$ & $2 \sigma$ \\
\hline & & & & & & & & \\
\hline 33.3 & & & & & 58 & 0.6 & 15 & 0.3 \\
\hline 25 & & & & & & & & \\
\hline 20 & & & & & 33 & 1.1 & 30 & 0.7 \\
\hline 17.6 & 11 & 1.7 & 233 & 4.4 & 21 & 0.5 & 60 & 1.2 \\
\hline 12.5 & & & & & 18 & 2.2 & 120 & 0.9 \\
\hline 11.1 & & & & & & & & \\
\hline 10 & & & & & & & & \\
\hline 5.3 & & & & & 3 & 0.2 & 300 & 1.6 \\
\hline
\end{tabular}

Table 5. Summary of PVA Oxidation data with $\mathrm{H}_{2} \mathrm{O}_{2}$ and UV (at $366 \eta \mathrm{m}$ ).

\subsection{Activation energy for PVA oxidation at $366 \eta \mathrm{m}$}

Three different oxidation reactions of 5\% PVA were carried out at temperatures of $28^{\circ} \mathrm{C}$ (normal room temperature reaction conditions), $35^{\circ} \mathrm{C}$ and $65^{\circ} \mathrm{C}$. The length of ultrasonic treatment was used as a means of increasing the reaction temperature of the mixtures. That is, the longer the sonication time the higher the reaction temperature of the mixture of PVA $/ \mathrm{H}_{2} \mathrm{O}_{2}$. Table 6 is a summary of the reaction rates at different temperature6. In these reactions hydrogen peroxide formed approximately 17.6 percent of the total solution volume; with 5\% PVA making up the difference in volume. The reaction rates increased with increasing reaction temperatures. Figure 11 is a plot of the natural log of the reaction rate constants versus the reciprocal of the reaction temperatures in degrees Kelvin. The slope of the line in Figure 11 is -4666.6 .

The slope of the line $=-\mathrm{Ea}$ (activation energy)/R (gas constant) .

$$
\mathrm{Ea}=4666.6(8.3144) \mathrm{JK}^{-1} \mathrm{Mole}^{-1}=38,800 \mathrm{JK}^{-1} \mathrm{Mole}^{-1}
$$

The calculated activation energy under these conditions is therefore approximately 39,000 $\mathrm{JK}^{-1} \mathrm{Mole}^{-1}$.

\begin{tabular}{|l|l|l|l|}
\hline $\begin{array}{l}\text { Reaction rate constant } \\
\left(\mathrm{min}^{-1}\right), \mathrm{K}\end{array}$ & $\begin{array}{l}\text { I/T ( T in degrees } \\
\text { Kelvin) }\end{array}$ & -Ln K & $\begin{array}{l}\text { Temperature } \\
\text { in degrees } \\
\text { Celsius }\end{array}$ \\
\hline & & & \\
\hline 0.0219 & 0.003321 & 3.821 & 28 \\
\hline 0.0331 & 0.003245 & 3.408 & 35 \\
\hline 0.1217 & 0.002957 & 2.106 & 65 \\
\hline
\end{tabular}

Table 6. Activation energy data for PVA oxidation at $366 \eta \mathrm{m}$ with ultrasonic treatment. 


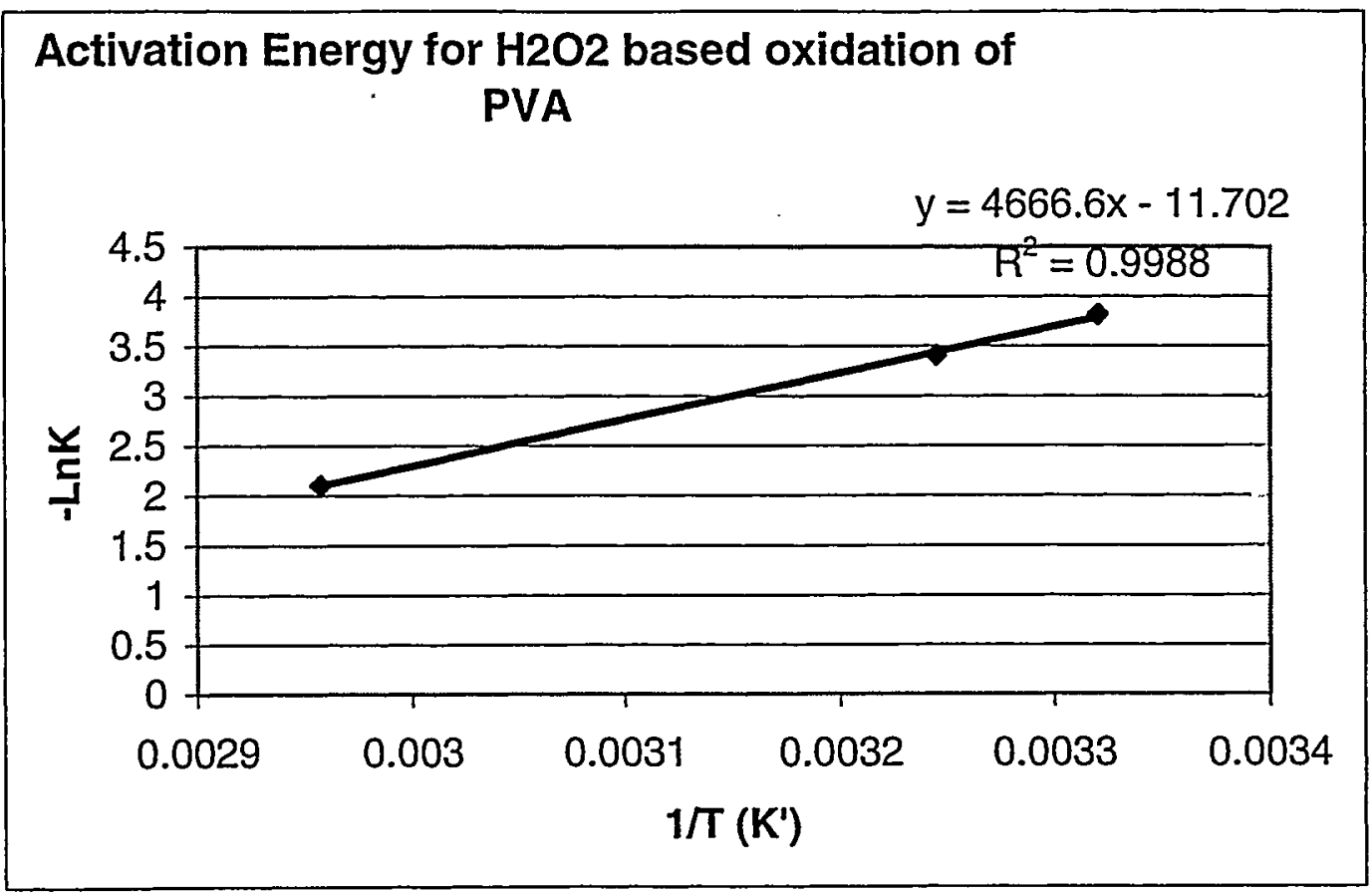

Figure 11. Activation energy plot for PVA oxidation with $\mathrm{H}_{2} \mathrm{O}_{2} / \mathrm{UV}(366 \eta \mathrm{m}) /$ Ultrasonic treatment.

\subsection{Photochemical oxidation of $\mathrm{H}_{2} \underline{\mathrm{O}}_{2} / \mathrm{PVA}$ at $302 \mathrm{~nm}$ with and without ultrasonic treatment.}

Procedure

The procedure is the same as in section 4.30 above except that the UV irradiation was now carried out at a wavelength of $302 \eta \mathrm{m}$ (Figures 18 and 19).

\section{Results}

Oxidation without sonication at $302 \mathrm{~nm}$

Figures $12 \mathrm{a}$ and $12 \mathrm{~b}$ below shows typical PVA oxidation profile per equation 6 Appendix $\mathrm{C}$ for PVA oxidation at $302 \eta \mathrm{m}$ with sonication. A typical reactions rate constant per equation 6, Appendix C (slope of the curve in Figure 12b is $0.0996 \mathrm{~min}^{-1}$ ). This is almost a factor of 5 better than reactions at $366 \eta \mathrm{m}$ above. The first four columns in Table 7 contains a summary of $5 \% \mathrm{PVA} / \mathrm{H}_{2} \mathrm{O}_{2} / \mathrm{UV}$ oxidation data at $302 \eta \mathrm{m}$ without sonication. Figure $13 \mathrm{a}$ and $13 \mathrm{~b}$ are, respectively, plots of percent hydrogen peroxide versus T-90 illumination time and reaction rate constant versus percent hydrogen with $U V$ and no ultrasonic treatment of the $\mathrm{PVA} / \mathrm{H}_{2} \mathrm{O}_{2}$ mixtures at $302 \eta \mathrm{m}$. 
Results

Oxidation with sonication at $302 \mathrm{~nm}$

Figure $14 \mathrm{a}$ and $14 \mathrm{~b}$ are similar plots to Figures $13 \mathrm{a}$ and $13 \mathrm{~b}$. However, this time it is oxidation of 5\% PVA with UV at $302 \eta \mathrm{m}$ coupled with continuous sonication of the reacting mixtures of PVA and $\mathrm{H}_{2} \mathrm{O}_{2}$. The last four columns in Table 7 shows a summary of the average data obtained. Based on the data obtained the reaction rate for the sonicated PVA $/ \mathrm{H}_{2} \mathrm{O}_{2}$ treatment at $302 \mathrm{\eta m}$ is about a factor of 3 better than runs without sonication. The same conclusions is more obvious when based on the magnitude of the slopes of the reaction rate versus percent hydrogen peroxide plots for PVA oxidation with and without ultrasonic treatment (Figures 10,13 and 14).

5.10 Oxidation products from Photochemical and sonochemical degradation of PVA. The oxidation products from the mineralization of PVA in hydrogen peroxide with only ultraviolet irradiation at both 302 and $366 \eta \mathrm{m}$ gave a colorless solution, which has been identified as mainly acetic and formic acids (14). Two overlapping peaks corresponding to formate and acetate peaks were observed with ion chromatographic analysis of oxidized PVA solution. With $\mathrm{pH}$ adjustment to alkaline conditions, using sodium hydroxide, the formation of the corresponding acid sodium salts are expected (sodium acetate and sodium formate). However, the oxidation products from combined ultraviolet irradiation and ultrasonic treatment of PVA in hydrogen peroxide gave a colored solution with yellow tinge. This also happens to be mainly a mixture of acetic and formic acids $(15,16)$ and based on the signal peak intensity and area the acetic peak is more pronounced. One can therefore conclude that there is more acetic acid species produced from this UV/ultrasonic treatment. This color difference seems to indicate that there exists an intrinsic difference in reactivity between radicals formed by photolysis and those formed by ultrasonic treatment (17), which would result in the formation of different end products for the oxidation of PVA. Severe oxidation of PVA with potassium permanganate has been reported to produce mainly oxalic acid and carbon dioxide (ref 14).

5.20 Estimation of amount of salt produced from $\mathrm{pH}$ adjustment of oxidized PVA. The main products from hydrogen peroxide-based oxidative mineralization of PVA (UV/ultrasonic treatment included) have been identified mainly as acetic and formic acids:

$$
\left[-\mathrm{CH}_{2}-\mathrm{CHOH}-\right] \mathrm{n} \text {----H2O2/UV/ultrasonic----- } \rightarrow \mathrm{CH}_{3} \mathrm{CO}_{2} \mathrm{H}+\mathrm{CH}_{2} \mathrm{O}_{2}
$$

The $\mathrm{pH}$ of the resulting solutions is $2.9 \pm 0.2$. To estimate the amount of organic salt formed from $\mathrm{pH}$ adjustment to 13.5 with sodium hydroxide $50 \mathrm{~mL}$ of the oxidized PVA solution was titrated with 1.0 molar solution of sodium hydroxide. $15 \mathrm{~mL}$ of 1.0 molar solution of sodium hydroxide was required to bring the $\mathrm{pH}$ of the oxidized PVA solution to about 13.5. This is equivalent to $12 \mathrm{~g}$ of sodium hydroxide per liter of $100 \%$ oxidized $5 \%$ PVA solution. The $\mathrm{pH}$ adjustment was carried out while the excess hydrogen peroxide in the oxidized PVA solution was being decomposed in alkaline conditions by heating the mixture. If one assumes that the $\mathrm{pH}$ adjustment results in the conversion of 
all the acids in solution to their corresponding acetate and formate salts of sodium per equation below, then the amount of salt formed can be estimated:

$\mathrm{NaOH}+\mathrm{CH}_{3} \mathrm{COOH} \rightarrow \mathrm{CH}_{3} \mathrm{COONa}+\mathrm{H}_{2} \mathrm{O}$ $-2$

$\mathrm{NaOH}+\mathrm{CHOOH} \rightarrow \mathrm{CHOONa}+\mathrm{H}_{2} \mathrm{O}$

From equation 2 above, stoicheiometrically, $82 \mathrm{~g}$ of sodium acetate salt is produce from the neutralization reaction per 40 grams of sodium hydroxide used. Therefore 24.6 grams of the acetate salt will be produced per liter of oxidized PVA solution ( $82 \mathrm{~g}$ acetate $/ 40 \mathrm{~g}$ $\left.\mathrm{NaOH}^{*} 12 \mathrm{~g} \mathrm{NaOH}\right)$. Similarly per equation 3 above, $68 \mathrm{~g}$ of sodium formate is produced from the neutralization reaction with $40 \mathrm{~g}$ of sodium hydroxide. This means $20.4 \mathrm{~g}$ of sodium formate is produced per liter of oxidized PVA (68 $\mathrm{g}$ formate $/ 40 \mathrm{~g}$ $\mathrm{NaOH}^{*} 12 \mathrm{~g} \mathrm{NaOH}$ ).

If one assumes that a liter of $100 \%$ oxidized PVA solution contains only acetic and formic acids in a 1:1 ratio then the estimated amount of salt in that solution would be 22.5 $\mathrm{g}$ per liter $((20.4+24.6) / 2)$ or 22.5 grams of salt per liter of oxidized PVA solution. Note that a litter of 5\%PVA solution initially (neat solution) contains 50 grams of PVA fabric. Hence, $22.5 \mathrm{~g}$ of salt per liter translates to approximately $0.05 \mathrm{lbs}$. of salt per liter of oxidized PVA or $0.45 \mathrm{lbs}$. of salt per pound of PVA material processed. Here secondary reaction effects, such as formation of oxides of carbon, which leads to decrease in salts produced was taken into consideration. Therefore, $0.45 \mathrm{lbs}$. of salt per pound of PVA material processed is the most amount of salt that can be produced.

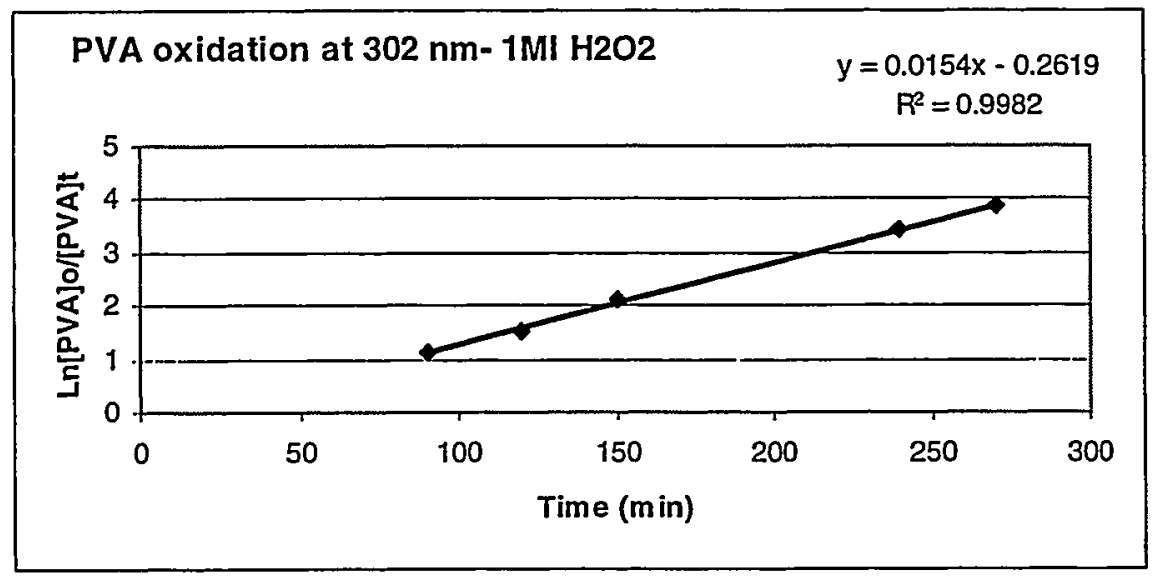

Figure 12a. A typical PVA oxidation profile per equation 6, Appendix C. 


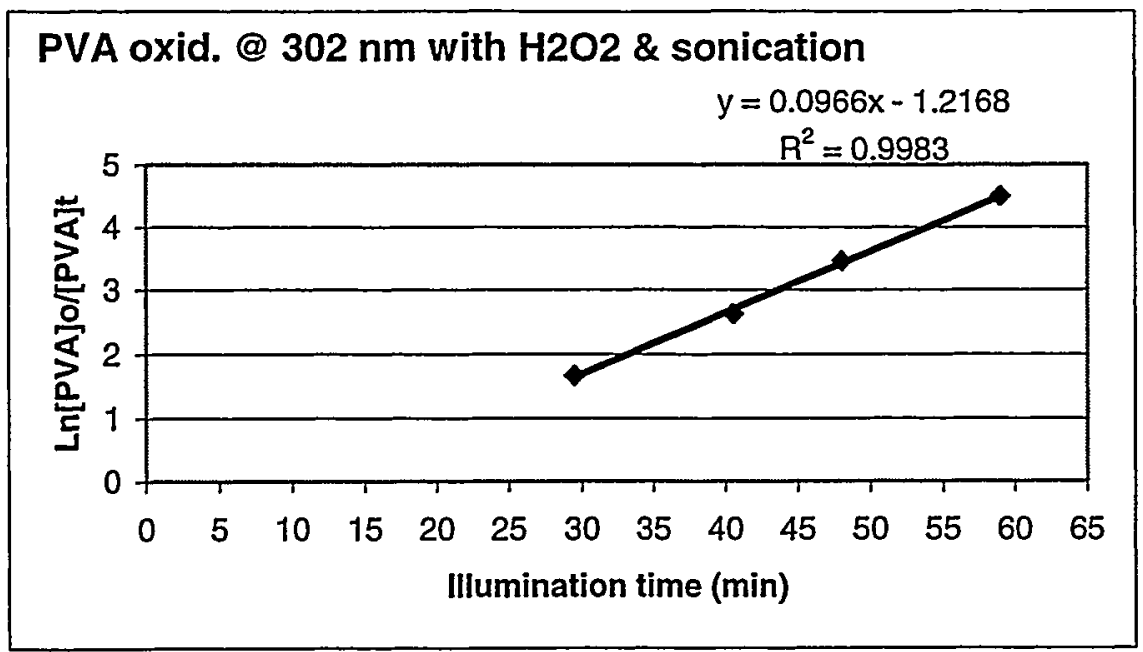

Figure 12b. A typical plot per equation 6 for PVA oxidation with $\mathrm{H} 2 \mathrm{O} 2 / \mathrm{UV}$ (@302 ๆm) with ultrasonic treatment.

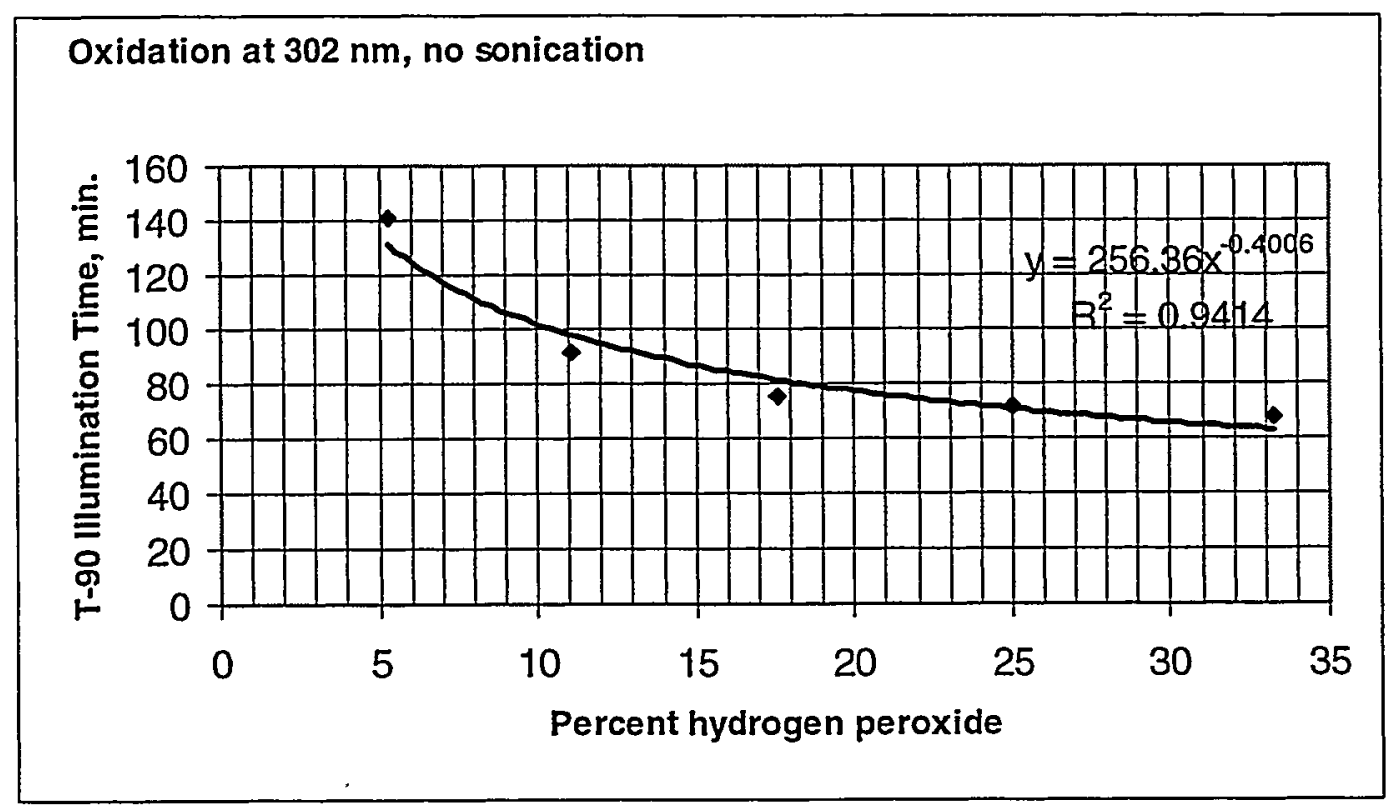

Figure 13a. Variation of illumination time (T-90) with percent hydrogen peroxide at 302 $\eta \mathrm{m}$ without ultrasonic treatment. T-90 is the minimum time required for a better than 90 percent mineralization of $5 \%$ PVA in $50 \%$ aqueous hydrogen peroxide. 


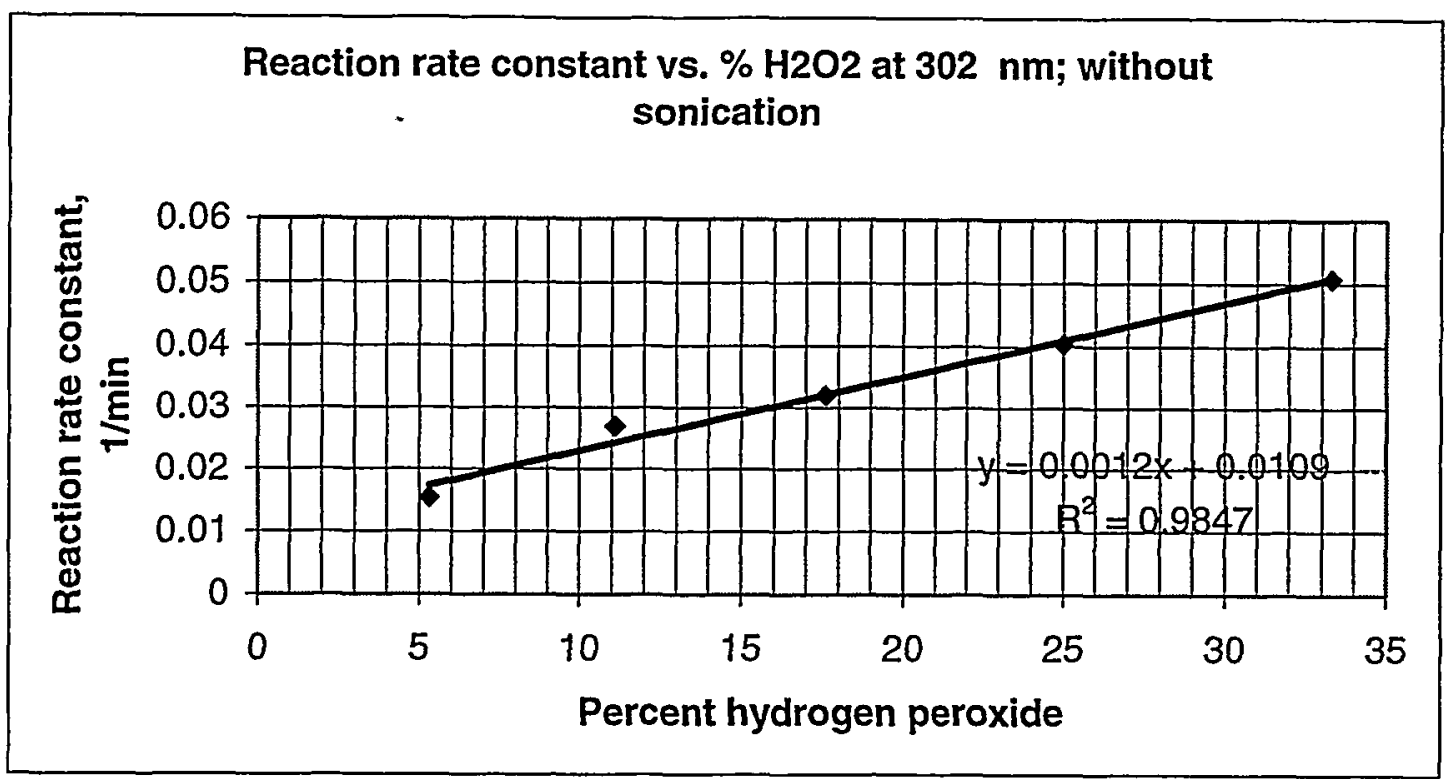

Figure 13b. Changes in reaction rate constant with percent hydrogen peroxide used in oxidative mineralization of $5 \%$ polyvinyl alcohol solution at $302 \mathrm{\eta m}$ without sonication.

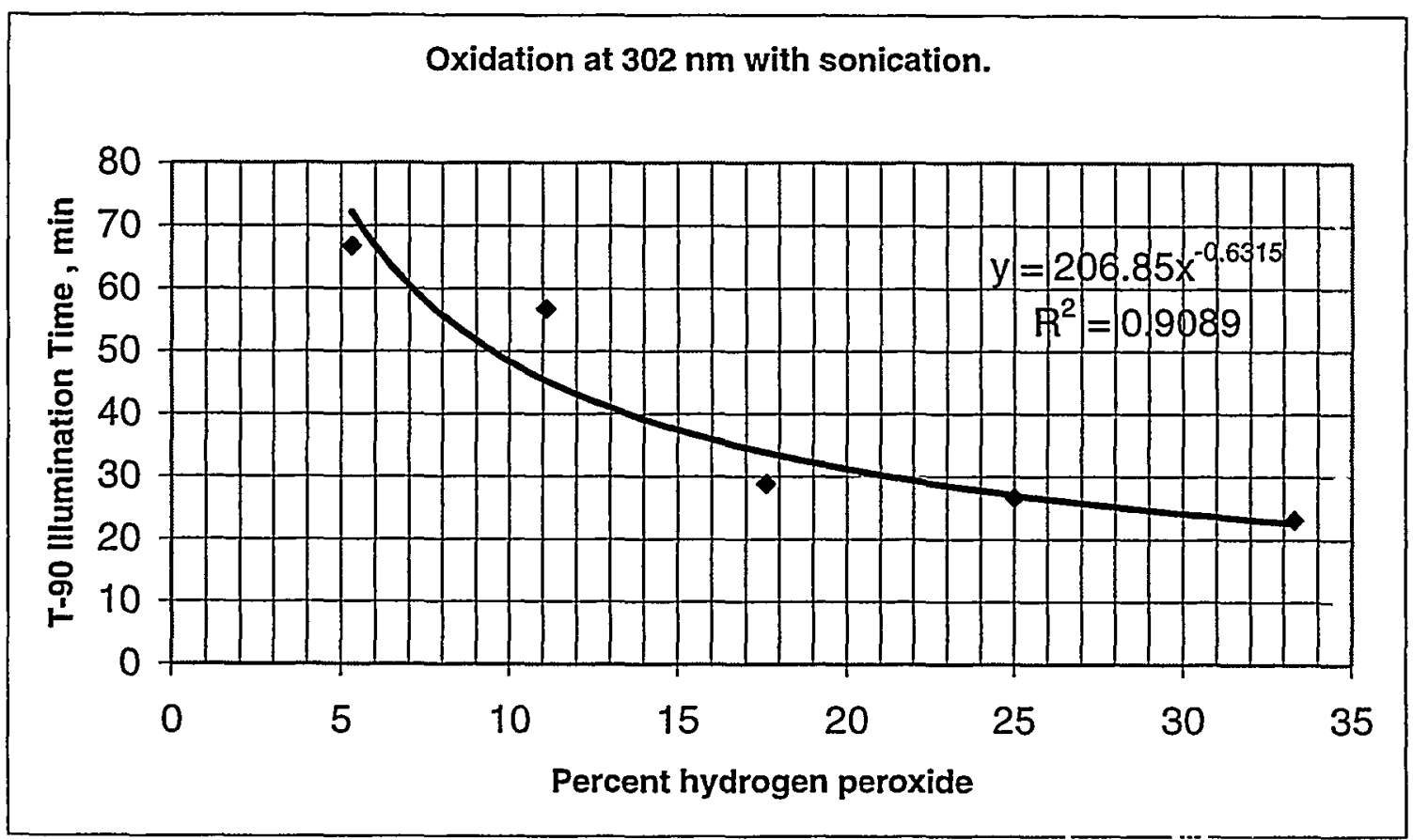

Figure 14a. Variation of illumination time (T-90) with percent hydrogen peroxide at 302 $\eta \mathrm{m}$ with ultrasonic treatment. T-90 is the minimum time required for a better than 90 percent mineralization of 5\% PVA in 50\% aqueous hydrogen peroxide. 
Reaction rate constant vs. $\% \mathrm{H} 2 \mathrm{O} 2$ at $302 \mathrm{~nm}$.

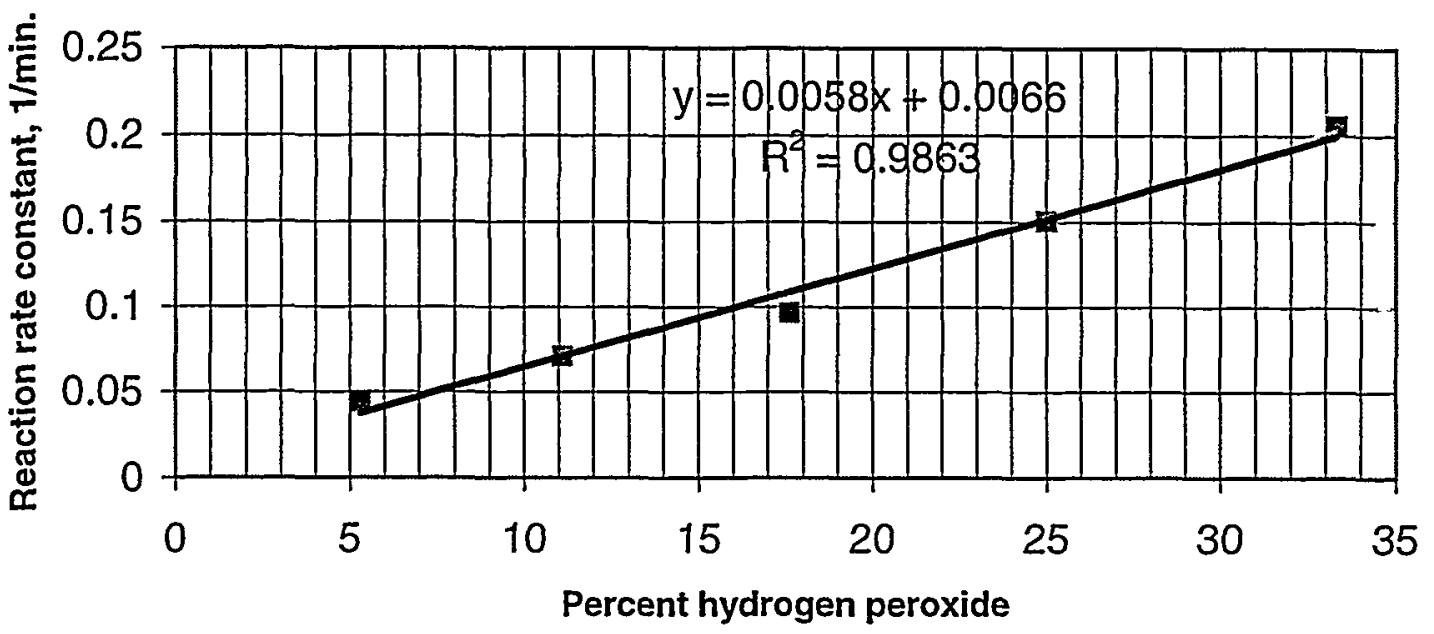

Figure 14b. Changes in reaction rate constant with percent hydrogen peroxide used in oxidative mineralization of $5 \%$ polyvinyl alcohol solution at $302 \eta \mathrm{m}$ with sonication

\begin{tabular}{|l|l|l|l|l|l|l|l|l|}
\hline & \multicolumn{3}{|l|}{ Without Sonication } & \multicolumn{4}{|c|}{ With sonication } \\
\hline$\%_{2} \mathrm{O}_{2}$ & $\begin{array}{l}\text { Rate*1000 } \\
\left(\mathrm{min}^{-1}\right)\end{array}$ & $2 \sigma$ & $\begin{array}{l}\mathrm{T}-90 \\
(\mathbf{m i n} .)\end{array}$ & $2 \sigma$ & $\begin{array}{l}\text { Rate*1000 } \\
\left(\mathrm{min}^{-1}\right)\end{array}$ & $2 \sigma$ & $\begin{array}{l}\text { T-90 } \\
(\mathbf{m i n} .)\end{array}$ & $2 \sigma$ \\
\hline & & & & & & & & \\
\hline 33.3 & 51 & 1 & 68 & 0.9 & 206 & 4 & 23 & 0.2 \\
\hline 25 & 40 & 0.6 & 71 & 1.4 & 151 & 1.3 & 27 & 0.5 \\
\hline 20 & & & & & & & & \\
\hline 17.6 & 32 & 0.6 & 75 & 1.1 & 97 & 2 & 29 & 0.3 \\
\hline 12.5 & & & & & & & & \\
\hline 11.1 & 27 & 0.3 & 91 & 1.8 & 71 & 1.4 & 57 & 1.2 \\
\hline 10 & & & & & & & & \\
\hline 5.3 & 15 & 0.4 & 141 & 2.8 & 44 & 0.9 & 67 & 0.9 \\
\hline
\end{tabular}

Table 7. Summary for PVA oxidation data with $\mathrm{H}_{2} \mathrm{O}_{2}$ and $\mathrm{UV}$ at $302 \mathrm{\eta m}$ 


\begin{tabular}{|l|l|}
\hline Target ion /precursor & $\begin{array}{l}\text { Average molar } \\
\text { concentration }\end{array}$ \\
\hline & \\
\hline $\begin{array}{l}\mathrm{Na}^{+} \text {(from all sodium } \\
\text { precursors) }\end{array}$ & 5.6 \\
\hline $\mathrm{Cs}^{+} / \mathrm{CsNO}{ }_{3}$ & 0.00014 \\
\hline $\mathrm{K}^{+} / \mathrm{KOH}$ & 0.015 \\
\hline $\mathrm{OH}^{-} / \mathrm{NaOH}, \mathrm{KOH}$ & 1.191 \\
\hline $\mathrm{NO}_{3}^{-} / \mathrm{NaNO}_{3}$ & 2.140 \\
\hline $\mathrm{NO}_{2} / \mathrm{NaNO}_{2}$ & 0.52 \\
\hline $\mathrm{AlO}_{2}^{-} / \mathrm{NaAlO}_{2}$ & 0.31 \\
\hline $\mathrm{CO}_{3}{ }^{-2} / \mathrm{Na}_{2} \mathrm{CO}_{3}$ & 0.16 \\
\hline $\mathrm{SO}_{4}{ }^{-2} / \mathrm{Na}_{2} \mathrm{SO}_{4}$ & 0.15 \\
\hline $\mathrm{Cl}^{-} / \mathrm{NaCl}^{\mathrm{NaCl}}$ & 0.025 \\
\hline $\mathrm{F} \mathrm{NaF}^{-} \mathrm{F}$ & 0.032 \\
\hline $\mathrm{PO}_{4}^{-3} / \mathrm{Na}_{2} \mathrm{PO}_{4.12 \mathrm{H}_{2} \mathrm{O}}$ & 0.01 \\
\hline $\mathrm{C}_{2} \mathrm{O}_{4}^{-2} / \mathrm{Na}_{2} \mathrm{C}_{2} \mathrm{O}_{4}$ & 0.008 \\
\hline $\mathrm{SiO}_{3}^{-2} / \mathrm{Na}_{2} \mathrm{SiO}_{3} .9 \mathrm{H}_{2} \mathrm{O}$ & 0.004 \\
\hline $\mathrm{MoO}_{4}^{-2} / \mathrm{Na}_{2} \mathrm{MoO}_{4}$ & 0.0002 \\
\hline
\end{tabular}

Table 8. SRS Tank Farm Average Waste Composition (WSRC-RP-98-01051).

\subsection{EVAPORATION AND COMPATIBILITY STUDIES FOR TANK FARM SIMULANT WITH OXIDIZED AND NEAT PVA SOLUTION}

\subsection{Tank Farm Simulants}

The average Tank Farm simulant waste composition used in this study is summarized in Table 8 above. The Tank Farm simulant, with an average sodium ion concentration of 5.6 molar, was spiked ${ }^{*}$ with $2 \%$ oxidized PVA solution. This spiked solution was used in the characterization of cesium-137 and plutonium-239 removal efficiencies with CST and MST ion exchange materials. A diluted spiked solution of the Tank Farm simulant, 4.7 molar sodium ion, was used for the characterization of cesium-137 removal from Tank Farm using TPB.

\subsection{Evaporation/mixing properties of Tank Farm simulant with oxidized PVA. Procedure}

Two, three and four percent PVA solution were prepared by serial dilution of neat five percent PVA solutions and 500-mL portions of each solution put into 1000 -mL beakers on a hot plate in a hood for continuous evaporation. The temperature of the hot plate was raised by $10^{\circ} \mathrm{C}$ every 20 minutes. The temperature of each heated beaker and its contents was monitored through the use of thermometers and thermocouples. The behavior of each PVA solution (2,3,4 and 5\%PVA) was monitored by looking for the formation of films of transparent PVA material on the beaker walls and around the general evaporation surface.

\footnotetext{
"Tank Farm area personnel recommended a $2 \%$ oxidized PVA spiking of Tank Farm simulant. This $2 \%$ value is considered a conservative representation of volume amount of oxidized PVA per chosen holding Tank in the Tank Farm system.
} 
The experiments were repeated with completely mineralized PVA solutions from both oxidation with hydrogen peroxide and acidified potassium permanganate.

To observe interactions between Tank Farm simulant and oxidized PVA and neat PVA solutions, such as number of different phases formed, equal volumes of oxidized PVA and Tank Farm simulant was mixed in 50-mL sampling vials. The same experiment was repeated with neat PVA solutions. The $\mathrm{pH}$ of hydrogen peroxide mineralized PVA solution was adjusted with 1.0 molar solution of sodium hydroxide until the solution $\mathrm{pH}$ was about 135. The resulting solution was treated with ultrasonic waves until all the excess hydrogen peroxide had been decomposed. This oxidized PVA solution, with no excess $\mathrm{H}_{2} \mathrm{O}_{2}$, was also mixed with Tank Farm simulant on a one-to-one basis.

\section{Results}

The evaporation beakers containing neat PVA solutions started showing evidence of formation of PVA films (skins) at about $70^{\circ} \mathrm{C}$. By the time the temperature of each solution had reached $85^{\circ} \mathrm{C}$ the entire evaporation surface of each beaker had been covered with thin transparent sheet of PVA film. After about six hours on the hot plate (average temperature of $98^{\circ} \mathrm{C}$ ) each of the beakers had lost all its water content and only the PVA films were visible (Figure 15).

With oxidized PVA solutions $\left(\mathrm{H}_{2} \mathrm{O}_{2}\right.$-based oxidation), under the same evaporation conditions, there were no films formed, and after about six hours there were no significant residue materials left on the bottom of each beaker. Oxidized PVA solutions derived from oxidation with potassium permanganate had a tendency to produce small amounts of black manganese dioxide precipitates on the sides of the evaporation vessel.

The mixing of even trace amounts of neat PVA with Tank Farm simulant resulted in the formation of white "fluffy cotton ball" precipitates or suspensions in solution, leading to two distinct phases. With about one percent of the neat PVA in the simulant solution a clearly white fluffy ball suspension was formed at room temperature. The reversal of the dissolution of PVA fabric in Tank Farm simulant was quite obvious (Figure 16).

The mixing of oxidized PVA with Tank Farm simulant, even on a one-to one bases, produced no obvious solid particles or precipitates. However, the initial colorless mixture turned orange, probably due to the oxidation of sulfur, which is present in trace amounts in the Tank Farm simulant. Since excess hydrogen peroxide was present in oxidized PVA solution the mixing of oxidized PVA with Tank Farm simulant led to the evolution of gases. This was probably due to the decomposition of hydrogen peroxide in an alkaline environment to produce oxygen gas. The mixing of oxidized PVA solution, in which excess hydrogen peroxide had been removed, with Tank Farm simulant did not result in the evolution of gases and no precipitation or formation of solid particles were observed. Therefore, before mixing of oxidized PVA waste with Tank Farm waste excess hydrogen peroxide must be removed by adjusting the $\mathrm{pH}$ to 12 while sonicating or heating the solution. 
Tank Farm simulant spiked with two or more percent completely oxidized PVA solution $\left(\mathrm{H}_{2} \mathrm{O}_{2}\right.$-based oxidation), when evaporated to dryness contained no PVA evaporation residue, scales or films of PVA. With drop in temperature (overnight) there were still no film or scaly evaporation products formed. Salt crystals from the simulant itself were formed during the heating and evaporation of the oxidized PVA and Tank Farm simulant.

\subsection{Efficiency of ion exchange-based radionuclide removal in the presence of oxidized PVA.}

\section{Procedure}

The determination of changes in the batch distribution coefficient, $\mathrm{k}_{\mathrm{d}}$, and decontamination factor for the uptake of radionuclides in the presence of Tank Farm simulant (5.6 $\left.\mathrm{M} \mathrm{Na}^{+}\right)$spiked with $2 \%$ oxidized PVA was carried out in the following manner. Twenty-five milliliters of the selected liquid per mixing vial were spiked with $0.5 \mathrm{~mL} \mathrm{Cs}-137$ (tracer) into each sample vial and mixed for 5 minutes. After mixing for 1 minutes, $1.0 \mathrm{ml}$ of the sample was sent for counting to get initial Cs-137 concentration. $1.0 \mathrm{gm}$ of CST was then added into each vial and the slurry mixed for 30 minutes and filtered through a 0.25 micron syringe filter. One milliliter of the filtrate was sent for gamma counting to obtain cesium-137 left in solution. Based on equation 2, Appendix B the batch distribution coefficient, $K_{d}$, was determined. The $K_{d}$ for Tank Farm simulant $\left(5.6 \mathrm{M} \mathrm{Na}^{+}\right)$containing no oxidized PVA was also determined in a similar fashion.

In evaluating changes in the decontamination factor, $D_{f}$, using TPB, $25 \mathrm{ml}$ of Tank Farm simulant $\left(4.7 \mathrm{M} \mathrm{Na}^{+}\right)$and Tank Farm simulant $\left(4.7 \mathrm{M} \mathrm{Na}^{+}\right)$containing $2 \%$ by volume oxidized PVA solution, were spiked with $0.75 \mathrm{mg}$ cold cesium and $1.0 \mathrm{~mL}$ of cesium-137 tracer. Initial cesium activity was in the range of 1.98 to $2.21 \mathrm{E} 05 \mathrm{~d} / \mathrm{min}-\mathrm{mL}$. $0.4 \mathrm{gm}$ of sodium tetraphenyl borate (NaTPB) was added to each solution and stirred. At the end of 30 minutes, the cesium-137 activity from the filtrate for each sample was determined. Similarly, $25 \mathrm{~mL}$ of the solutions (Tank Farm simulant $\left(5.6 \mathrm{M} \mathrm{Na}^{+}\right)$and Tank Farm simulant containing $2 \%$ by volume oxidized PVA solution) were spiked with Sr- 90 . The samples were treated with flow-sheet-level monosodium titanate slurry and the solutions agitated overnight. Samples for analysis were syringe filtered before submission for analysis. The above procedure was repeated with plutonium-239 tracer. Based on modified form of equation 2, Appendix B, the decontamination factors for cesium-137, strontium- 90 and plutonium-239 were calculated. See Table 9 below.

Results

The results for the uptake of principal Tank Farm radionuclides (Cs-137, Sr-90, Pu-239) are summarized in Table 9. There are no significant differences in the magnitudes of decontamination factors or batch distribution coefficients for the uptake of radionuclides in the presence of oxidized PVA solution in Tank Farm simulants. 


\begin{tabular}{|l|l|l|l|}
\hline Radionuclide/resin & $\begin{array}{l}\mathrm{K}_{\mathrm{d}} \text { or } \mathbf{D}_{\mathrm{f}} \text { for Tank Farm } \\
\text { simulant, } \\
\left(4.7 \mathrm{M} \mathrm{Na}^{+}\right)\end{array}$ & $\begin{array}{l}\mathrm{K}_{\mathrm{d}} \text { or } \mathbf{D}_{\mathrm{f}} \text { for 2\% PVA spiked Tank } \\
\text { Farm simulant, ml/g }\end{array}$ & $\begin{array}{l}\text { Tank Farm simulant, } \\
(5.6 \mathrm{M} \mathrm{Na}), \mathrm{m} / \mathrm{g}\end{array}$ \\
\hline Cs-137/CST & $2366, \mathrm{~K}_{\mathrm{d}}$ & $2354\left(5.6 \mathrm{M} \mathrm{Na}^{+}\right), \mathrm{K}_{\mathrm{d}}$ & $1619, \mathrm{~K}_{\mathrm{d}}$ \\
\hline Cs-137/TPB & $282\left(\mathrm{D}_{\mathrm{f}}\right)$ & $302\left(\mathrm{D}_{\mathrm{f}}\right)\left(4.7 \mathrm{M} \mathrm{Na}^{+}\right)$ & $249\left(\mathrm{D}_{\mathrm{f}}\right)$ \\
\hline Sr-90/MST & $20\left(\mathrm{D}_{\mathrm{f}}\right)$ & $19\left(5.6 \mathrm{M} \mathrm{Na}^{+}\right)\left(\mathrm{D}_{\mathrm{f}}\right)$ & Not applicable \\
\hline $\mathrm{Pu}-\mathrm{MST}$ & $>30\left(\mathrm{D}_{\mathrm{f}}\right)$ & $23\left(5.6 \mathrm{M} \mathrm{Na}^{+}\right)\left(\mathrm{D}_{\mathrm{f}}\right)$ & $21\left(\mathrm{D}_{\mathrm{f}}\right)$ \\
\hline
\end{tabular}

Table 9. Batch distribution coefficients and decontamination factors for ion exchange removal of target radionuclides from Tank Farm simulant and Tank Farm simulant spiked with $2 \%$ oxidized PVA. No significant changes in magnitudes of $D_{f}$ or $K_{d}$ observed in the presence of oxidized PVA solution.

\subsection{Complexing/hydrolysis of radionuclides with products of PVA oxidation and reagents}

Procedure

Cold cesium $(0.1 \mathrm{mg} / \mathrm{L})$ and strontium $(0.1 \mathrm{mg} / \mathrm{L})$ solutions from cesium and strontium nitrate precursors, respectively, were spiked with almost equal volumes of oxidized PVA solutions. The resulting solutions were monitored at room temperature for any evidence of precipitation of cesium or strontium. After a couple of hours, portions of the solution were mixed with Tank Farm simulant for further observation. The other portion of the solutions was filtered through a 0.2 -micron Nalgene ${ }^{\circledR}$ filter.

$\underline{\text { Results }}$

Both spiked strontium and cesium solutions did not show any evidence of precipitation of cesium or strontium at room temperature and at that $\mathrm{pH}$. There were no evidence of solid particles formed when cesium/strontium spiked solution was mixed with Tank Farm simulant. Filtering the solutions through a 0.2 -micron Nalgene ${ }^{\circledR}$ filter left no solid residues on the filter membrane.

Although a measure of $D_{f}$ and $K_{d}$ values above, indicate no effects on ion-exchange properties in the presence of oxidation products, the potential exists for the complexing of products of PVA oxidation and even hydrogen peroxide with radionuclies like plutonium and other trivalent actinides and lanthanides. The extent of complexing of each radionuclide with the oxidation products (acetates from oxidation with $\mathrm{H}_{2} \mathrm{O}_{2}$ and oxalate from oxidation with $\mathrm{KMnO}_{4}$ ) depends on the concentration of the radionuclide and $\mathrm{pH}$ of the waste stream. At high $\mathrm{pH}$ conditions, depending on the oxidation states of plutonium species present in any waste stream, the potential for the formation of plutonium hydroxides increases. These hydroxides of plutonium would eventually precipitate.

\subsection{Determination of changes in total organic carbon for oxidized and neat PVA..} Procedure

The Analytical Development Section (ADS) at SRTC determined the total organic carbon for neat 5\% PVA and 100\% oxidized PVA solutions based on ADS procedures.

\footnotetext{
'Precipitation of cesium-137; decontamination factor, $D_{f}$, measured and not $k_{d}$.
} 
$\underline{\text { Results }}$

The average total organic carbon for neat 5\% PVA and 100\% oxidized PVA solutions were, respectively $25,700 \pm 200 \mathrm{mg} / \mathrm{L}$ and $18,900 \pm 210 \mathrm{mg} / \mathrm{L}$. This is about $26.5 \%$ less carbon in oxidized PVA. This may be attributed to reactions leading directly to carbon dioxide gas formation. A total organic carbon content of $18,900 \mathrm{mg} / \mathrm{L}$ shows that although most of the neat PVA had been mineralized, the oxidation products (acetic and formic acids) are mostly in solution. With $\mathrm{pH}$ adjustment, using sodium hydroxide, these carboxylic acids are converted to their corresponding sodium salts and in a radiation environment, the carboxylic salts will be radiolytically decomposed to carbon dioxide and inorganic sodium salts mainly.

\subsection{DISCUSSIONS AND CONCLUSIONS}

Even at room temperatures, the direct mixing of Tank Farm simulant with neat PVA (unmineralized) solution, in all proportions, results in the precipitation of solid insoluble PVA balls. Neat PVA solutions have a tendency to form transparent polymer films (skins) when subjected to temperatures greater than $70^{\circ} \mathrm{C}$. Therefore, neat PVA waste solutions are not appropriate for processing through the SRS Tank Farms.

Both acidified and unacidified potassium permanganate solutions and solid crystals can be used for the complete mineralization of 5\%PVA to simpler organic compounds. This oxidation of PVA with potassium permanganate is rapid, being practically complete in a few minutes at room temperature. Acidified potassium permanganate is relatively more efficient in this oxidative mineralization of $5 \%$ PVA, because it has a higher oxidation potential ( 1.51 Volts) than neutral or alkaline permanganate solution (1.23 Volts). The resulting PVA waste solution from oxidation with unacidified potassium permanganate, with a $\mathrm{pH}$ greater than 10 , may require no further $\mathrm{pH}$ adjustment. However, because of the potential for the formation of solids, mostly black manganese dioxide $\left(\mathrm{MnO}_{2}\right)$ during $\mathrm{pH}$ adjustment in the Tank Farm process, oxidation of 5\%PVA with aqueous $50 \%$ hydrogen peroxide in the presence of UV light at $302 \mathrm{\eta m}$ with ultrasonic treatment (sonication) is preferred.

PVA oxidation products, using hydrogen peroxide or potassium permanganate, are mainly acetic and formic acids, although other acids like oxalic acid may be produced with permanganate oxidation of PVA. These carboxylic acids, in the presence of a neutralizing base like sodium hydroxide, are converted to their corresponding salts (formate, acetate and oxalate salts). There may also be further degradation of acetates to formates, carbon dioxide and water if oxidation is carried out with sonochemical/UV photochemical treatment in the presence of hydrogen peroxide. The $\mathrm{pH}$ of mineralized PVA solution based on hydrogen peroxide oxidation is less than 3.2. Hence, a pH adjustment with preferably sodium hydroxide, would be required to bring the $\mathrm{pH}$ value above 9.7 (Tank Farm WAC requirements). Excess hydrogen peroxide will have to be destroyed by heating the PVA waste solution between $70-85^{\circ} \mathrm{C}$. This destruction of excess hydrogen peroxide can be successfully carried out during $\mathrm{pH}$ adjustment by sonicating the oxidized PVA waste matrix. 
Given enough time and under laboratory conditions, it was observed that at room temperature a $1.0 \mathrm{~mL} \mathrm{H}_{2} \mathrm{O}_{2}$ mixed with $19 \mathrm{~mL} \mathrm{5 \%}$ PVA solution had the same PVA oxidation efficiency (extent of PVA conversion to carboxylic acids) as a $3.0 \mathrm{~mL} \mathrm{H}_{2} \mathrm{O}_{2}$ mixed with $17 \mathrm{~mL} \mathrm{5 \%} \mathrm{PVA.} \mathrm{Unlike} \mathrm{the} \mathrm{rapid} \mathrm{kinetics} \mathrm{observed} \mathrm{at} \mathrm{room} \mathrm{temperature} \mathrm{for}$ PVA (5\%) oxidation with permanganate ion, the oxidation of PVA with hydrogen peroxide is a slower reaction at room temperature and has multiple reaction mechanism pathways. Two principal reaction sequences are obvious (Appendix C): decomposition of hydrogen peroxide into the peroxides (hydroxyl radicals mainly) and the reaction of the peroxides with PVA.

In these PVA oxidation reactions one of the goals was to determine an adequate volume of $\mathrm{H}_{2} \mathrm{O}_{2}$ that could be used to obtain a reasonable conversion (better than 90\%) of PVA to minimize the overall volume of liquids waste generated from PVA oxidation. However, because of the slower reaction rates observed in the oxidation of 5\% PVA with hydrogen peroxide at room temperature, and the steady increase in reaction rates in the presence of UV and ultrasonic treatments, it was difficult to adequately address the question of minimum $\mathrm{H}_{2} \mathrm{O}_{2}$ required without further study.

However, based on information in Figures 10,13 and 14, for any chosen percent hydrogen peroxide used in the oxidation of 5\% PVA, the corresponding reaction rate constant and time required for a better than $90 \%$ mineralization of PVA can be determined by extrapolation. The parameters obtained from these plots are only valid for oxidation at the corresponding wavelength at which the plots were obtained with ultrasonic energy at $4.6 \mathrm{Watt} / \mathrm{cm}^{2}$ and UV energy at $2,350 \mathrm{Watt} / \mathrm{m}^{2}$.

The oxidation of 5\% PVA in the presence of UV light (at $302 \eta \mathrm{m}$ ) coupled with continuous ultrasonic treatment provided the best PVA oxidation results.

Based on neutralization reactions between acidic solutions from PVA oxidation products and sodium hydroxide the amount of organo-sodium salts, which could be produced from $\mathrm{pH}$ adjustments of oxidized PVA solution (sodium acetate and sodium formate) have been estimated. The estimated amount of combined sodium salts produced from $\mathrm{pH}$ adjustment reactions to is $22.5 \mathrm{~g}$ per liter $(0.2 \mathrm{lbs}$. of salt per gallon of oxidized PVA) or $0.45 \mathrm{lbs}$. of salt per pound of PVA material processed.

The carboxylic moieties from the oxidation of PVA do not seem to have any detrimental effect to ion exchange techniques used for the extraction of radionuclides from Tank Farm waste or induce chelating or precipitating of the radionuclides under alkaline conditions. However, plutonium in its lower oxidation states $\left(\mathrm{Pu}^{+3}\right.$ and $\left.\mathrm{Pu}^{+4}\right)$ and under low $\mathrm{pH}$ conditions, for example, readily forms weak acetate $\left(\mathrm{Pu}\left(\mathrm{C}_{2} \mathrm{H}_{3} \mathrm{O}_{2}\right)^{2+}\right)$ and oxalate $\left(\mathrm{Pu}\left(\mathrm{C}_{2} \mathrm{O}_{4}\right)_{2}{ }^{+}\right)$complexes and possibly formate complexes $\left(\mathrm{Pu}\left(\mathrm{HCO}_{2}\right)^{2+}\right)$, too. (19). Other higher oxidation states of plutonium complex less effectively. On the other hand, any weak organic complexes, such as those formed between organic moieties and plutonium ion may be destroyed under radiolytic conditions such as those that exist in the Tank Farms. It is also worth noting that at high $\mathrm{pH}$ conditions, depending on the oxidation 
states of plutonium species present in any waste stream, the potential for the formation of plutonium hydroxides increases. These hydroxides of plutonium would eventually precipitate.

Plutonium is capable of complexing with hydrogen peroxide in acidic conditions $(\mathrm{pH}<3)$ to form a plutonium peroxy-complex [HO-Pu-OO-Pu-OOH $\left.]^{4+}\right]$. With the addition of $\mathrm{H}_{2} \mathrm{O}_{2}$ to a solution containing reasonable amounts of tetravalent plutonium the color of the solution changes from brown to red leading to eventual precipitation of insoluble tetravalent plutonium peroxide. The color change is due to the formation of higher peroxy plutonium complexes. However, $\mathrm{H}_{2} \mathrm{O}_{2}$ is destroyed by strong base; the addition of sodium hydroxide before discharge to waste tanks would destroy excess $\mathrm{H}_{2} \mathrm{O}_{2}$ and any $\mathrm{Pu}-\mathrm{H}_{2} \mathrm{O}_{2}$ complexes.

Because of the possibility of precipitating plutonium complexes from either the organic, peroxy and hydroxide complexes the design of the PVA oxidation reactor must take criticality concerns into consideration. This is especially the case if $\mathrm{Pu}-239 / 241$ isotopes are present in the PVA waste stream.

There are several other approaches to the oxidative degradation of PVA in the presence of hydrogen peroxide. Surface modification of transition metal oxide catalysts such as $\mathrm{TiO}_{2}$ or doping of lanthanides $(6,7,18)$ and the application of photo-Fenton reaction (generation of hydroxyl radicals via photo-induced electron transfer from water to excited $\left.\mathrm{Fe}^{3+}\right)(8-11)$, to name a few, are commercially available. However, these other organic degradation enhancement techniques may not be compatible with the Tank Farm process at SRS. For example, these techniques require the introduction of solid catalyst materials into the waste stream. Above all, these catalyst-based enhancement techniques seem to perform well only with ground water containing organic compounds in the lower ppb (ug/L) to low ppm (mg/L) levels. In addition, solid catalysts in ppb levels may introduce unwanted side reactions under high alkaline conditions of the Tank Farm waste streams.

Table 10 contains a summary of some the advantages of photochemical/sonochemical treatment over the other commercial techniques involving transition metals oxides and hydrogen peroxides. In addition, UV photolysis and sonochemical treatment suppresses the recombination of hydroxyl radicals, which is a common reaction pathway in plain $\mathrm{H}_{2} \mathrm{O}_{2} / \mathrm{UV}$ technique. The coupling of sonochemical treatment with UV photolysis also generates aqueous electrons and increases the reaction temperatures, which further enhances the degradation of unwanted organic compounds (12-13). 
WSRC-RP-99-00524, Rev 0.0

Page 34 of 48

\begin{tabular}{|l|l|}
\hline$\underline{\mathrm{H}}_{2} \mathrm{O}_{2} / \mathrm{UV} /$ Sonochemical Treatment & $\mathrm{H}_{2} \underline{\mathrm{O}}_{2}$ /UV/transition metal oxidation of PVA \\
\hline No coating problems with organics & $\begin{array}{l}\text { Organic coating on catalyst surface may impede } \\
\text { catalytic actions. }\end{array}$ \\
\hline No solids introduced in waste matrix & $\begin{array}{l}\text { Solids from spent catalyst may pose problems to } \\
\text { waste stream processing. }\end{array}$ \\
\hline $\begin{array}{l}\text { Generates aqueous electrons and extra } \\
\mathrm{OH}^{-1} \text { for further degradation of organics }\end{array}$ & Transition metals act only as a catalyst. \\
\hline $\begin{array}{l}\text { Increase in reaction rate with increase in } \\
\text { temperatures due to sonic energy. }\end{array}$ & Temperature increase is limited. \\
\hline $\begin{array}{l}\text { Enhances excess } \mathrm{H}_{2} \mathrm{O}_{2} \text { decomposition } \\
\text { with pH adjustment to alkaline } \\
\text { conditions. }\end{array}$ & Requires external thermal heat supply \\
\hline $\begin{array}{l}\text { No organic problems and no interference } \\
\text { with Tank Farm ion exchange process. }\end{array}$ & $\begin{array}{l}\text { Catalysts are often transition metal organics, } \\
\text { which may interfere with Tank Farm ion } \\
\text { exchange chemistry. }\end{array}$ \\
\hline $\begin{array}{l}\text { Works even at higher organic } \\
\text { concentrations (\% organic) }\end{array}$ & $\begin{array}{l}\text { Works best at ppb or lower ppm organic } \\
\text { concentrations }\end{array}$ \\
\hline $\begin{array}{l}\text { Long history of operation before } \\
\text { replacement of parts. }\end{array}$ & $\begin{array}{l}\text { May cost more in terms of catalyst procurement } \\
\text { and regeneration. }\end{array}$ \\
\hline
\end{tabular}

Table 10. Summary of advantages and disadvantages of photochemical/sonochemical/ $\mathrm{H}_{2} \mathrm{O}_{2}$ treatment of organic waste over $\mathrm{H}_{2} \mathrm{O}_{2}$ transition metal catalyst treatment.

Since the $\mathrm{pH}$ of the final PVA waste solution will be adjusted to alkaline conditions the potential for the formation of explosive organo-nitrates would be eliminated.

Waste solutions containing greater than $90 \%$ mineralized PVA, when mixed with Tank Farm waste, are not expected to adversely affect the rheological (pumpability, PVA film formation, coagulation and precipitation of solid PVA) and evaporation (skin or film formation with changes in solution temperature) properties of Tank Farm solutions.

The magnitude of the batch distribution coefficient and decontamination factors, which are an equilibrium measure of the overall ability of a solid phase ion exchange material to remove ions of interest from solution, were found to be equal for Tank Farm simulant solutions with and without $2 \%$ oxidized PVA. Therefore, efficiencies for cesium-137, strontium-90, and plutonium removal from the Tank Farm, using ion exchange resins (CST and MST) and precipitating agents (TPB), are not affected by the presence of oxidized PVA. It is worth noting that more than a minimum $D_{f}$ or $K_{d}$ values were obtained in all radionuclide extractions, by appropriate agents, in the presence of $2 \%$ oxidized PVA solutions.

The viscosity of a completely mineralized 5\% PVA solution is about 1.0 centipoise as opposed to 32 centipoise for neat 5\% PVA solution (18). The density of oxidized PVA is $0.99 \mathrm{~g} / \mathrm{cc}$ and that of neat $5 \%$ PVA solution is $1.05 \mathrm{~g} / \mathrm{cc}$. The $\mathrm{pH}$ of a freshly prepared 
5\% PVA solution is approximately 7 . With time, the $\mathrm{pH}$ drops to less than 7 . See Appendix D for Tank Farm compatibility summary for PVA and oxidized PVA solutions.

No radiolysis or hydrogen generation experiments were carried out with oxidized PVA solutions in Tank Farm simulants to evaluate the long or short-term effects of radiation on the stability of oxidized PVA products (Acetate and formate anions from PVA oxidation with $\mathrm{H}_{2} \mathrm{O}_{2}$ and oxalates anion from permanganate oxidation). However, based on aqueous radiolytic chemistry the introduction of oxidized PVA solution into the High Level Waste (HLW) system will not increase the production of flammable gases during storage and processing of the HLW. Radiolysis of acetate, formate and oxalate anions will produce oxides of carbon (e.g.carbon dioxide and carbonate), $\mathrm{H}_{2} \mathrm{O}_{2}$ and hydrogen as stable radiolytic products. Since the oxidation of PVA will be carried out in an open oxygen-rich environment, the methane formation is highly unlikely. The primary reducing species in the radiolytic decomposition of water and the anions from PVA oxidation (formate, acetate and oxalate) are aqueous electrons and hydroxyl radicals. In the oxygen-rich environment, aqueous electrons will more often react to produce oxygen -based radicals instead of hydrogen radicals that are precursors for hydrogen production.

Assuming no nitrate and nitrite inhibitor effects on hydrogen production due to $\alpha$ and $\beta / \gamma$ radiolysis, the g-value (number of hydrogen molecules per $100 \mathrm{eV}$ absorbed) for hydrogen generation from radiolysis of water is equal in magnitude $(0.45 \mathrm{for} \beta / \gamma$ radiolysis) to the g-values for hydrogen generation from the radiolysis of formate and oxalate anions in oxygenated solutions $(21,22)$. In comparison, the average carbon dioxide and hydrogen peroxide g-values from radiolysis of oxalate ion $\left(\mathrm{g}-\left[\mathrm{CO}_{2}\right]\right.$ and g$\left.\left[\mathrm{H}_{2} \mathrm{O}_{2}\right]\right)$ are, respectively, 5.5 and $3.9(22)$. Hence, the main stable products of radiolytic decomposition of these PVA oxidation products are mostly carbon dioxide and hydrogen peroxide. The hydrogen g-value from the radiolysis of the acetate anion in an alkaline condition is not well documented in literature, but based on the number of hydrogen atoms per mole of the acetate anion in comparison with water the g-value could only be 0.68 at most. Even in a worst case scenario, if one assumes purely $\alpha$-radiolytic activities the hydrogen generation value from the decomposition of acetate anion could not exceed 1.3 hydrogen molecules per 100 electron volts absorbed by the acetate anion (22). Therefore, the hydrogen generating g-value from each PVA oxidation product is within the range of values for water due to both $\beta / \gamma$ and $\alpha$ radiolysis $[0.45$ for $\beta / \gamma$ radiolysis and 1.5 for $\alpha$ radiolysis.

Thus we conclude that the addition of oxidized PVA solutions into the HLW system does not increase the production of flammable compounds during storage and processing of HLW. 


\subsection{RECOMENDATIONS AND PATH FORWARD}

Based on the above results the following recommendations are made:

- Neat PVA solution will not meet Tank Farm Waste Acceptance Criteria and thus must to be chemically degraded before its introduction into the Tank Farms process.

- Since a 4\% PVA solutions is easier to prepare and oxidize, this percent PVA should be the preferred target solution for PVA conversion in hot water and subsequent mineralization.

- A hydrogen peroxide based oxidation of PVA in the presence ultraviolet (UV) light at $302 \eta \mathrm{m}$ and ultrasonic treatment $\left(4.6 \mathrm{Watts} / \mathrm{cm}^{2}\right)$ is recommended for the mineralization of PVA solution.

- The expected reaction rate per chosen percent aqueous hydrogen peroxide relative to the total PVA waste volume to be mineralized can be obtained from a reaction rate versus percent hydrogen peroxide plots. Similarly, the time required for a better $90 \%$ conversion of PVA can be obtained from T-90 versus percent hydrogen peroxide plots.

- The recommended UV intensity at this wavelength is about $2,350 \mathrm{Watts} / \mathrm{M}^{2}$.

- Since the possibility for the complexing of plutonium with both hydrogen peroxide and acetic acid to form, respectively, the plutonium peroxy and acetate complexes, engineering conditions must be established to minimize possible criticality problems.

- Oxidized PVA solution $\mathrm{pH}$ must be adjusted to about 10 and excess hydrogen peroxide destroyed before introducing of oxidized PVA solution into the Tank Farms.

- Design and scale up of PVA oxidation equipment will require a reaction vessel probably made of pyrex ${ }^{\circledR}$ or quartz glass for maximum transmission of UV energy.

- The interior of such reaction vessel should be coated with a thin film of Teflon ${ }^{\circledR}$ material to minimize internal corrosion and chemical degradation due to alkaline or acidic conditions.

- An ultrasonic device with multiple probes, capable of delivering at least 4.6 Watts $/ \mathrm{cm}^{2}$ of ultrasonic energy and a moderate shearing device or blender will need to be incorporated into the reaction vessel design.

- Because of safety, ways to incorporate remote handling or containment for processing heavily contaminated radioactive PVA solution wastes will be needed.

- The reaction vessel should be equipped with a chemical handling system (Oxidants) with appropriate safety features.

- Appropriate safety devices to handle excess gas releases and pressure changes within the reaction vessel are necessary.

- Pilot scale studies are recommended for additional process optimization prior to development for operational deployment.

- Companies to contact for design and scale up of this type of PVA dissolution and oxidative mineralization equipment include Calgon Carbon corporation (Frank Swearington at 704-662-3594) and Isolyzer of Norcross Georgia (D. W. Velmonsky at 770-806-9898 ext. 263).

- A more rigorous cost analysis should be performed based on the results of these experiments before more development work is carried out. 


\subsection{QUALITY CONTROL}

All experimental work reported in this document was conducted in accordance with QA controls and procedures given in WSRC-1Q, and SRTC Conduct of Research and Development (WSRC-1M-97-00024, Rev.1). Experimental data are recorded in laboratory notebooks WSRC-NB-99-00076 and WSRC-96-655. Other relevant documents to this report include WRSC-TR-99-00044, Rev. 0 (TTP) and WSRC-TR-9900045 Rev. 0 (QA plan).

\subsection{ACKNOWLEDGEMENTS}

The author wishes to thank the following people who contributed to this work: Dr. D. G. Karraker of the Chemical Hydrogen Technology Section for investigating ion-exchange material/precipitating agent compatibility with oxidized PVA and Ray Roberts of the Analytical Development Section for ion chromatography analysis of oxidized PVA. Funding for this study was provided by Solid Waste.

The information contained in this article was developed during the course of work under Contract No. DE-AC09-96SR18500 with the U. S. Department of Energy. 


\subsection{REFERENCES}

(1) Winer, A. M., G. M. Breuer, W. P L. Carter., K. R. Darnall, and J. N. Pitts, jr., “ Effects of Ultraviolet Spectra Distribution on the Photo-chemistry of Simulated Polluted Atmospheres," Atmos. Environ., 13, 989 (1979.

(2) Klavetter, E. A, Brown, N. NE., Trudell, D. E., Anthony, R. G., Gu, D, and Thibaud-Erkey, C, “ Ion-Exchange Performance of crystalline silicotitanate for Cesium Removal from Hanford Tank Waste Simulants", Waste Management 04, p. 709, Tucson, AZ.

(3) Keith B. Hanson, "Colorimetric Determination of PVOH" Procedure \# 617, Rev. 1. April 30, 1998. Air Products and Chemicals, Inc. 7201 Hamilton Boulevard, Allentown, PA 18195-1501 (800-345-3148 Ext. 71291. E-mail hansenkb@apci.com or www.airproducts.com

(4) Jaeger, C.D.; Bard, A.J., Journal of Phys. Chem. 1979,83,3146.

(5) Korman, C.;Bahnemann,D.W.; Hoffmann, M.R., Environ.Sci. \& Technol. $1988,22,798$.

(6) Augugliaro, V.; Daavi, E.; Palmisanto,L. Schiavello,M. and Sclafani, A. Appl. Catal. 1990,65,101.

(7) Tanaka, K., Hisanaga, T.; and Harada,K. Journal of Photochem. Photobio. A: Chem. 1989, 48, 155.

(8) Bauer. R; Fallman,H. Res.Chem. Intermed. 1997,23,341

(9) Kiwi, J; Pulgarin,C.; Peringer,P. App. Catal. B: Environ. 1994,3,335

(10) Wei,T.; Wang, Y.; Wan,C. Journal of Photochem. Photobiol A: Chem. 1990, $55,115$.

(11) Walling, C, Acc. Chem .Res. 1975, 125,8.

(12) Okouchi, S.; Nojima, O ; and Arai, T. Wat. Sci. Tech. Vol. 26, NO. 9-11, pp 2053-2056, 19992.

(13) Thomas, G; Gleason, M; and Popov, V. Environmental Progress vol. 17, No.3, pp. $154-160,1998$.

(14) C. A. Finch, "Chemical Reactions and stereochemistry of polyvinyl alcohol," $2^{\text {nd }}$ Edition, Edited by C. A. Finch, John Wiley \& Sons Ltd,. 1992

(15) Ikada Y. Nishizaka Y. and Sajurada I., J. Polym. Sci., Polym. Chem., 15,451 (1977).

(16) G. Mino, S. Kaizerman, and E. Rasmussen, J. Polym. Sci., 39, 523 (1959).

(17) Takahide K., Mitsue F., Hajime S., and Takashi A., J. Org. Chem., 1998, 63, 6719 C. A. Finch, "Polyvinyl alcohol-Properties and applications" $1^{\text {st }}$ Edition, Edited by C. A. Finch, and John Wiley, Chichester, 1973, pp220-1.

(18) Hans W. Maurer (Westvaco Corporation, New York, N.Y.) US. Pat. 3,859,269 U.S. Cl 260/91.3VA,260/29.6 WA

(19) J. M. Cleveland, "The Chemistry of Plutonium", $2^{\text {nd }}$ printing, Chapters 4 and 5 American Nuclear Society (1979).

(20) M. A. K. Mostafa, J. Polym. Sci., 28, 519-536 (1958)

(21) G. Ivan Draganic and Zorica D. Draganic, "The radiation of water", Academic Press, New York and London, 1971.

(22) I.G. Draganic and O. Gal, Radiation Res. Rev., 3 167-207 (1971). 


\section{APPENDIX A:}

PVA Analytical Procedure: Colorimetric determination of polyvinyl alcohol in solution.

This procedure, adapted from reference 3 , is used to quantify percent concentrations of PVA in dilute aqueous solutions such as those obtained from the dissolution of PVA fabric material in hot water.

\section{Analytical Principle:}

In dilute concentrations, PVA forms stable green colored complexes with iodine (18) in the presence of boric acid (assume starch is not present in solution to be characterized using this method). Note that in high PVA concentrations the color of the resulting solution with iodine/boric acid is dark blue.

The absorbance of the of the sample solution is measured and compared with a calibration curve prepared from the same grade of PVA that is in the sample to be analyzed. The determined maximum absorbance for this PVA/iodine/boric acid complex is around $670 \eta \mathrm{m}$.

\section{Apparatus:}

A single or dual beam UV-VIS spectrophotometer (300-1000 ๆm range)

\section{Reagents}

Distilled water, ACS reagent grade Boric acid and Iodine (99.999+ \%)

Potassium iodide, ACS reagent grade

Polyvinyl alcohol fabric (89-96 \% hydrolyzed) or standard solution from Air Products company.

\section{Reagent and Sample Preparation}

(1) Boric acid solution: $40 \mathrm{~g}$ dissolved in distilled water and diluted to $1000 \mathrm{ml}$ with distilled water ( $4 \%$ boric acid solution).

(2) Iodine solution: $12.7 \mathrm{~g}$ of iodine, and $25 \mathrm{~g}$ of potassium iodide, dissolved in and diluted to $1000 \mathrm{ml}$ with distilled water.

(3) Polyvinyl alcohol intermediate stock and standard solutions: Dry about 3 grams of PVA fabric pieces ( 0.5 by 1 inche) in a vacuum oven overnight at $50^{\circ} \mathrm{C}$. Bring about 1.5 liters of distilled water to near boiling in a sizeable beaker.

Weight out exactly 0.1000 grams of the PVA fabric pieces (4 decimal places of accuracy) and quantitatively prepare a $0.5 \%$ PVA solution by dissolving the 0.1000 grams of PVA fabric in $20-\mathrm{mL}$ volumetric flask (add while stirring). Bring to volume with hot distilled water. After the dissolution and cooling of the PVA solution, quantitatively transfer 10$\mathrm{mL}$ of the PVA solution to a $1000-\mathrm{mL}$ volumetric flask and bring to volume with hot distilled water (0.0050 \% PVA intermediate stock solution). Based on aliquot samples 
below prepare the calibration standard. Quantitatively transfer aliquot samples to a 100 $\mathrm{mL}$ volumetric. Add $20 \mathrm{~mL}$ of $4 \%$ boric acid solution and $6 \mathrm{~mL}$ of iodine solution to each $100-\mathrm{mL}$ flask and bring to volume with distilled water. Note that the blank solution (standard 0.0 ) contains only $20 \mathrm{~mL}$ of $4 \%$ boric acid solution and $6 \mathrm{~mL}$ of iodine solution brought to volume with distilled water.

\begin{tabular}{|l|l|l|}
\hline Standard \# & mL of intermediate stock per 100 mL & \%PVA in standard \\
\hline $\mathbf{0 . 0}$ & $\mathbf{0 . 0}$ (iodine and boric acid in water) & $\mathbf{0}$ \\
\hline 1 & 1.0 & 0.00005 \\
\hline 2 & 3 & 0.00015 \\
\hline 3 & 5 & 0.00025 \\
\hline 4 & 8 & 0.00040 \\
\hline 5 & 10 & 0.00050 \\
\hline 6 & 15 & 0.00075 \\
\hline 7 & 20 & 0.00100 \\
\hline 8 & 25 & 0.00125 \\
\hline 9 & 30 & 0.00150 \\
\hline
\end{tabular}

Table of calibration standards.

Perform a wavelength scan with the number 4 standard above from 500 to $800 \mathrm{~nm}$ to determine maximum absorption band $(\lambda \max )$. Measure the absorbance of the standards at $\lambda$ max. The calibration curve is derived from the absorbance values at $\lambda$ max plotted against the percent PVA $100-\mathrm{mL}$.

\section{Determination of Percent PVA left in solution after oxidation.}

During or after the oxidation of PVA the percent mount of PVA left in solution can be determined by transferring $0.1 \mathrm{ml}$ of the solution to $100-\mathrm{mL}$ flask already containing (dilution factor of 1000) $20 \mathrm{~mL}$ of $4 \%$ boric acid solution and $6 \mathrm{~mL}$ of iodine solution. The $100-\mathrm{mL}$ flask is brought to volume with distilled water. After shaking the contents of the flask to ensure uniformity, the absorbance of the sample is taken and the result compared to the calibration curve. During the mixing or shaking of the flask if precipitates are seen, mostly blue/green in color, the sample should be discarded. The absorbance of the oxidized sample solution has to lie within the absorbance range of the calibration standards.

\section{Quality assurance}

Glassware and pipetting equipment used in this test should be cleaned well, and in the case of the calibration standards new pipettes and mixing vessels should be used each time. Low levels of PVA in solution can adhere to glassware and cause false readings. 


\section{APPENDIX B}

\section{Batch Distribution coefficient Determination}

The sorption of radioactive nuclides present in Tank Farm simulant as spiked solutions (cesium onto CST, cesium onto TPB, and Plutonium and strontium-90 onto MST) was studied by batch technique. The general method used for these studies is described below:

The batch distribution coefficient $\left(\mathrm{K}_{\mathrm{d}}, \mathrm{mL} / \mathrm{g}\right)$ is an equilibrium measure of the overall ability of a solid phase ion exchange material to remove ions of interest from solution. It represents the theoretical volume of solution that can be processed per a given mass of the ion exchanger under equilibrium conditions (2). In these tests, a known quantity of the resin (approximately 0.1 grams) was placed in contact with $25 \mathrm{ml}$ of the simulant in a $50-\mathrm{ml}$ polyethylene bottle. All samples were prepared in duplicates. The polyethylene bottles were placed in an orbital shaker and the mixture agitated for 24 hours at $26 \pm 2$ ${ }^{\circ} \mathrm{C}$. After this contact time, the used resin was separated from the solution by filtering with a 0.2 microns nylon filter. The decanted portion, without resin was submitted for metal concentration analysis. The $\mathrm{K}_{\mathrm{d}}$ value was obtained by determining the concentration of metal ions of interest before and after contact and calculating the amount of metal ions of interest on the resin by difference. $\mathrm{K}_{\mathrm{d}}$ calculation was based on the equation below:

$$
K_{d}=\frac{C_{i}-C_{f}}{C_{f}}\left(\frac{V}{m * F}\right)
$$

Where $C_{i}$ is the initial metal of interest concentration, $C_{f}$ if the final metal of interest concentration after contact, $\mathrm{V}$ is the volume of simulant used, $\mathrm{m}$ is the resin exchanger mass and $\mathrm{F}$ is the $\mathrm{F}$-factor (ratio by weight of dry resin to wet resin). In the above equation, it is assumed that the mass of dry ion exchange is approximately equal to that of wet ion exchange material used; $\mathrm{F} \approx 1.0$. For radioactive samples or simulants spiked with radionuclides, $\mathrm{K}_{d}$ values were determined radiometrically by using the following equation:

$$
K_{d}=\frac{A_{i}-A_{f}}{A_{f}}\left(\frac{V}{m}\right)
$$

Where $A_{i}$ and $A_{f}$ are the activities of the radionuclide in solution at the beginning and at the end of sorption respectively, $v$ is the volume in $\mathrm{ml}$ of the solution used for equilibration and $w$ is the weight of the adsorbent in grams.

The decontamination factor, $\mathrm{D}_{\mathfrak{f}}$, is defined as initial concentration over final concentration. 


\section{APPENDIX C}

Kinetics of PVA Oxidation with hydrogen peroxide under UV light. Hydrogen peroxide acting as an oxidizing agent is added to the PVA solution and its decomposition to form peroxides, for example hydroxyl radicals, is activated by UV light. The peroxides (hydroxyl radicals) then react with the PVA, initiating a rapid cascade of oxidation reactions that ultimately mineralize the PVA (4).

$$
\begin{array}{ll}
\mathrm{H}_{2} \mathrm{O}_{2}+\mathrm{h} v(\mathrm{UV}) \rightarrow \text { peroxides }\left(\mathrm{OH} ;\left(\mathrm{O}_{2} \mathrm{H}\right)^{-},\left(\mathrm{H}_{2} \mathrm{OOH}\right)^{\dagger}\right) & 1 \\
\text { Peroxides + PVA } \rightarrow \text { products } & 2
\end{array}
$$

In equation 1 above the photo-dissociation of hydrogen peroxide results in the production of powerful oxidizing radicals (hydroxyl, hydroperoxide, peroxonium and peroxide ions). The peroxides are the principle agents responsible for the oxidative mineralization of PVA (equation 2). Per equation 1 and 2 the oxidation of PVA is a complex and irreversible consecutive set of reactions.

A Pyrex $®$ glass sample receptacle was used for all the UV studies because it shows a greater than 90\% UV transmission in the $366 \eta \mathrm{m}$ region (1) (Quartz-based sample tubes were also used for comparison). Mercury lamps $(\lambda=366,302$, and $254 \eta \mathrm{m})$ were used as a photo-dissociation energy source for the photolytic decomposition of hydrogen peroxide. The corresponding energies per Mole are, respectively, $327 \mathrm{KJ} / \mathrm{Mole}$ (longer wave UV energy source at $366 \eta \mathrm{m}$ ), $396 \mathrm{KJ} / \mathrm{Mole}$ (intermediate longwave at $302 \mathrm{\eta m}$ ), and $471 \mathrm{KJ} / \mathrm{Mole}$ (shortwave at $254 \mathrm{\eta m}$ ). The energy data are obtained by converting wavelength in $\eta \mathrm{m}$ to energy units $\mathrm{E}$ (KJ/Mole) by converting $E=1.1962 \mathrm{E} 05 / \lambda \mathrm{KJ} / \mathrm{Mole}$. The mercury lamp UV sources are not monochromatic (Hg source has broad wavelength distribution and the output is not tunable).

The rate of decomposition of hydrogen peroxide with the absorption of photon energy (equation 1 ) is given by

$$
\frac{-d\left[\mathrm{H}_{2} \mathrm{O}_{2}\right]}{d t}=\Phi \frac{\left[\mathrm{H}_{2} \mathrm{O}_{2}\right] d[h \nu]_{a b s}}{d t}
$$

Where $\Phi$ is the quantum yield for hydrogen peroxide degradation with the absorption of photon energy, and $d[\mathrm{~h} v]_{\mathrm{abs}} / \mathrm{dt}$ is the photon flux. Per equation 3 , the steady state concentration of $\mathrm{H}_{2} \mathrm{O}_{2}$ in the aqueous media is assumed to be dependent on the absorbed photon flux. However, in excess of micro-mole quantities of $\mathrm{H}_{2} \mathrm{O}_{2}$ concentration this may not be the case (5). Therefore, the solution to equation 3 becomes extremely difficult to solve for unique values. Since the quantitative kinetic calculation for this complex photo-dissociation of $\mathrm{H}_{2} \mathrm{O}_{2}$ is not straightforward, the apparent reaction rate constant for the mineralization of PVA in the presence of $\mathrm{H}_{2} \mathrm{O}_{2}$ will be based on initial PVA concentration and its concentration changes with time.

From equation 2 above, 
Peroxides + PVA---- $\frac{\mathrm{K}_{1}}{----\rightarrow} \rightarrow$ Products.

$\frac{-d[P V A]}{d t}=\mathrm{K}_{1}[$ peroxides $][P V A]$

If equation (4) is integrated, noting that at time, $t=0$, concentration of products $=$ 0 , then

$$
\operatorname{Ln} \frac{[P V A]_{o}}{[P V A]_{t}}=\mathrm{K}_{1}[\text { Peroxides }] \tau
$$

If it is assumed that $\mathrm{K}_{1}[$ Peroxides $]=$ constant, $\mathrm{K}_{2}$, ( $\tau$.is time), then

$$
\operatorname{Ln} \frac{[P V A]_{o}}{[P V A]_{t}}=\mathrm{K}_{2} \tau
$$

A plot of the left-hand side of equation 6 versus $\tau$ should yield a straight line with the slope equal to $\mathrm{K}_{2}$. Here, we have assumed that $\mathrm{K}_{2}$ represents the apparent reaction rate constant for the oxidative mineralization of PVA.

The UV light intensities (at $1 \mathrm{~cm}$ ) on the irradiated $\mathrm{PVA} / \mathrm{H}_{2} \mathrm{O}_{2}$ samples in a circular petridish are calculated as power per unit area of exposure or Watt per square meter. For the petri-dishes $(5.7 \mathrm{~cm}$ by $1.2 \mathrm{~cm})$ the intensity is

$$
\frac{6 \mathrm{Watt}}{0.785(5.7 \mathrm{~cm})^{2}}=2,352.5 \frac{\text { Watt }}{\mathrm{m}^{2}} \text {. }
$$

\section{Sonochemical treatment and viscocity measurements}

In runs were ultrasonic wave (sonication treatment) was used to further enhance the oxidation of PVA, a $20 \mathrm{kHz}$ ultrasonic generator (Labsonic $2000 \mathrm{U} / \mathrm{Braun}-\mathrm{sonic}$ ) with its energy output maintained at $4.58 \mathrm{Watts} / \mathrm{cm}^{2}$ was used. Here it is assumed that there is a minimum ultrasonic intensity below which there is no enhanced degradation of PVA in the presence of $\mathrm{H}_{2} \mathrm{O}_{2}$. Based on the work of Mostafa (20), 3.125 Watts $/ \mathrm{cm}^{2}$ was chosen as this threshold intensity for PVA. The test samples were either put in a $150-\mathrm{ml} \mathrm{Teflon}^{\circledR}$ beaker or in a $150-\mathrm{ml}$ Pyrex ${ }^{\circledR}$ glassware. For simultaneous sonication and UV radiation treatment of the PVA in hydrogen peroxide samples the UV lamp was aligned along the side of the beaker inside a sonication chamber (see Figure 18, and 19). In oxidation reactions not involving sonication the PVA/hydrogen peroxide mixtures were put into 5.7 $\mathrm{cm}$ by $1.2 \mathrm{~cm}$ petri-dishes sitting on a small laboratory jack under the mercury UV lamp (Figure 17). 


\section{Viscosity measurement}

Absolute viscosity measurements were based on forced-piston principle ${ }^{\circledR}$; where electromagnetic coils drive an internal piston up and down inside a measurement chamber filled with oxidized PVA or neat PVA solution

\footnotetext{
${ }^{\circledR}$ TCV 300 viscometer from Cambridge Applied System Inc., Medford, MA.
} 


\section{APPENDIX D}

\section{Compatibility summary for neat and oxidized PVA solutions with Tank Farm waste.}

\begin{tabular}{|c|c|c|c|}
\hline & Tank Farm concern & Neat PVA solution & Oxidized PVA Solution \\
\hline $\mathbf{1}$ & $\begin{array}{l}\text { Skin/film formation with } \\
\text { evaporation }\end{array}$ & $\begin{array}{l}\text { Significant residue formed with } \\
\text { evaporation. }\end{array}$ & $\begin{array}{l}\text { No skins or other residues } \\
\text { formed with evaporation. }\end{array}$ \\
\hline 2 & $\begin{array}{l}\text { PVA Precipitation/decomposition } \\
\text { in TF waste environment. }\end{array}$ & $\begin{array}{l}\text { TF simulant spiked with neat } \\
\text { PVA produces white cotton balls. } \\
\text { Reversal of PVA fabric } \\
\text { dissolution. }\end{array}$ & $\begin{array}{l}\text { Mixture with TF simulant } \\
\text { produces single-phase solution. } \\
\text { No solids observed. }\end{array}$ \\
\hline 3 & $\begin{array}{l}\text { Partition between evaporator overhead } \\
\text { (condensate) and salt solution }\end{array}$ & $\begin{array}{l}\text { Skin formed at } 70^{\circ} \mathrm{C} \text { little or no } \\
P V A \text { in vapor phase. }\end{array}$ & $\begin{array}{l}\text { Goes into vapor phase. No } \\
\text { residues or solid. }\end{array}$ \\
\hline 4 & Pumpability & $\begin{array}{l}\text { Transparent films formed with } \\
\text { changes in temperature. }\end{array}$ & $\begin{array}{l}\text { Pumpable in all proportions } \\
\text { with } T F \text { simulant. } \\
\end{array}$ \\
\hline 5 & $\begin{array}{l}\text { Nitration instead of oxidation during } \\
\text { acid based minerlization of PVA }\end{array}$ & $\begin{array}{l}\text { Oxidation with } \mathrm{H}_{2} \mathrm{O}_{2} / \mathrm{UV} \\
\text { recommended. } \mathrm{NO} \text { acid oxid. }\end{array}$ & $\begin{array}{l}\mathrm{PH} \text { adjustment with } \mathrm{NaOH} \\
\text { required. Enhances excess } \\
\mathrm{H}_{2} \mathrm{O}_{2} \text { decomposition. } \\
\end{array}$ \\
\hline 6 & $\begin{array}{l}\text { Precipitation/Chelation of radionuclides } \\
\text { in TF }\end{array}$ & Test not performed & $\begin{array}{l}\text { None observed with Cs-133 and } \\
\text { Sr-88 simulants }\end{array}$ \\
\hline 7 & $\begin{array}{l}\text { Reduction of effectiveness of } \mathrm{IX} \\
\text { materials in the removal of } \\
\text { radionuclides. }\end{array}$ & Test not performed & $\begin{array}{l}\text { No problems with CST and TPB } \\
\text { Awaiting results for } M S T\end{array}$ \\
\hline 8 & Oxidation products. & $\begin{array}{l}\text { Formate and acetate. Formate } \\
\text { mostly at } 302 \mathrm{~nm}\end{array}$ & $N A$ \\
\hline 9 & $\begin{array}{l}\text { Oxidation products and TF WAC } \\
\text { (CLFL problem?) }\end{array}$ & $\begin{array}{l}\text { No problem (CLFL of } 11) \text { for } \\
\text { pure formate and acetate. }\end{array}$ & $N A$ \\
\hline 10 & $\begin{array}{l}\text { Oxidation products and filtration } \\
\text { through } 0.5 \text { micron filters? }\end{array}$ & $\widehat{N A}$ & $\begin{array}{l}\text { Goes through a } 0.2 \text { micron } \\
\text { filter with no problems. }\end{array}$ \\
\hline 11 & $\begin{array}{l}\text { Radiolytic/degradation products? }\left(\mathrm{H}_{2}\right. \\
\text { generation) }\end{array}$ & $\begin{array}{l}\text { Test not performed (Information } \\
\text { will be based on plant } \\
\text { experience). }\end{array}$ & $\begin{array}{l}\text { Test not performed } \\
\text { (Information will be based on } \\
\text { plant experience) }\end{array}$ \\
\hline 12 & $\begin{array}{l}\text { Impact of oxidized PVA waste stream } \\
\text { on water balance in TF? }\end{array}$ & Test not performed & Test not performed \\
\hline 13 & $\begin{array}{l}\text { Less than } 0.005 \text { gallons of organics per } \\
\text { gallon of aqueous waste? (i.e.; } 19 \mathrm{ml} \\
\text { organic /Liter of PVA waste). }\end{array}$ & $\begin{array}{l}\text { Fails this Tank Farm WAC } \\
\text { Two distinct phases. }\end{array}$ & $\begin{array}{l}\text { Single phase, WAC not } \\
\text { applicable }\end{array}$ \\
\hline 14 & PH adjustment & NA & Required \\
\hline 15 & Viscosity & $30 \pm 2 \mathrm{cP}$ & $1 \pm 0.1 \mathrm{cP}$ \\
\hline 16 & Density & $1.05 \pm 0.02 \mathrm{gm} / \mathrm{cc}$ & $0.99 \pm 0.02 \mathrm{gm} / \mathrm{cc}$ \\
\hline
\end{tabular}




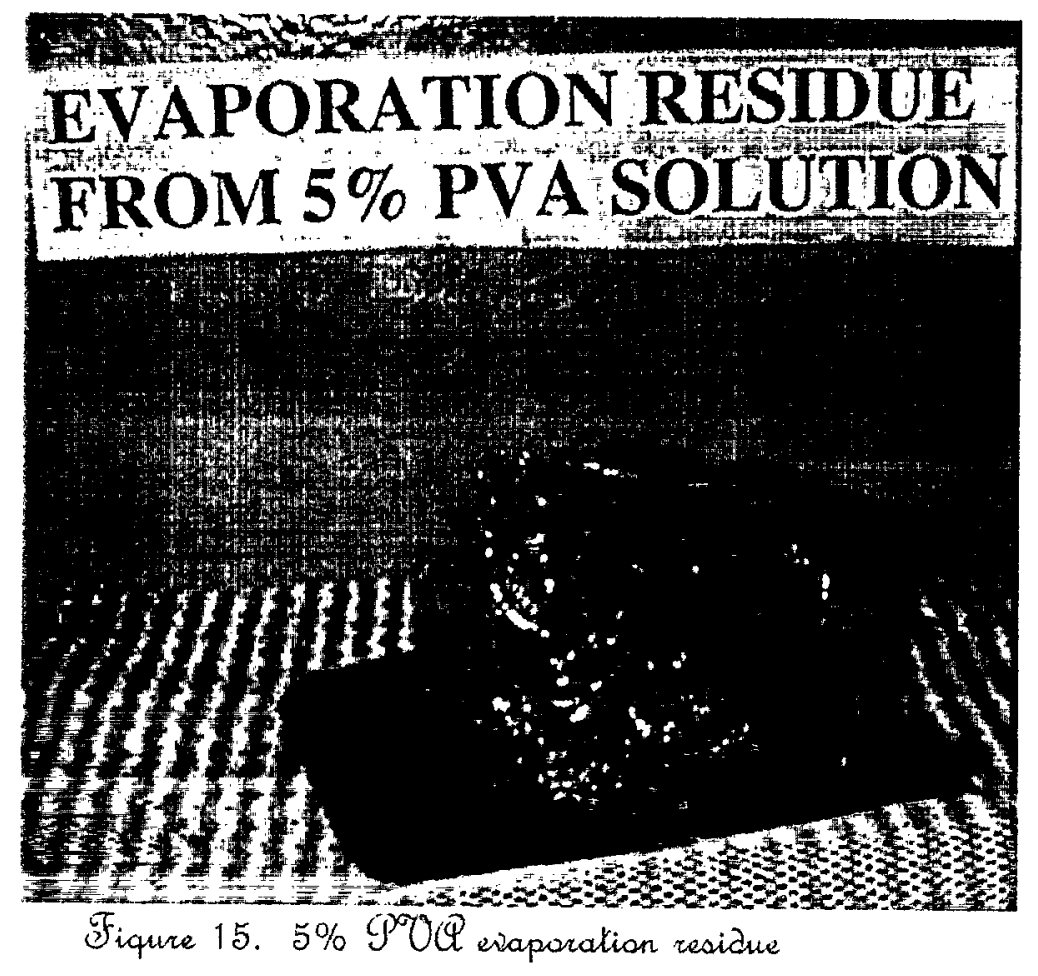

Figure 15. Neat 5\% PVA evaporation residue

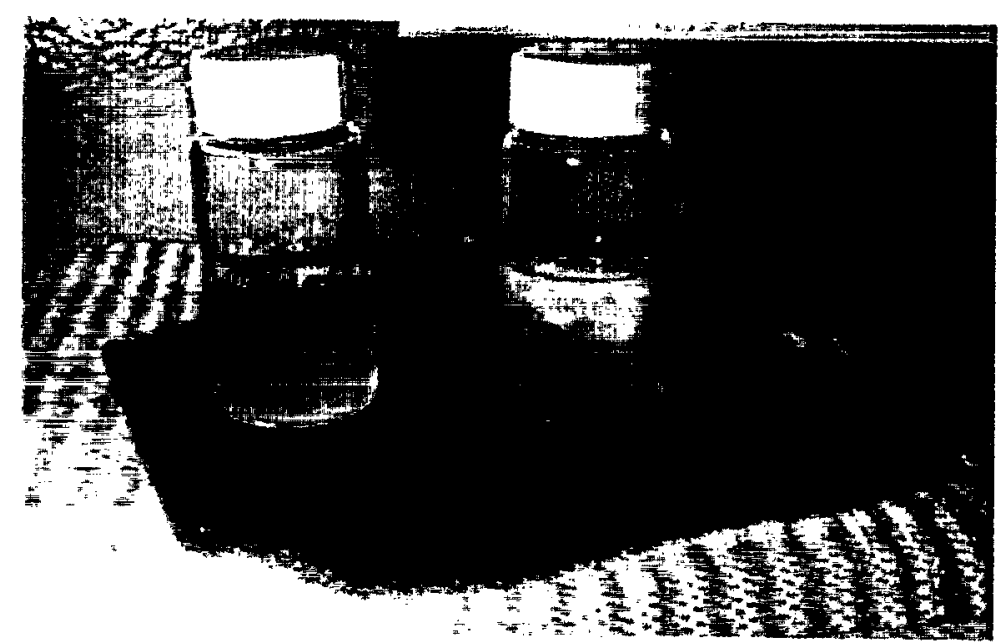

Figure 16. Neat (right vial) and oxidized (left vial) PVA in Tank Farm simulant. Neat PVA forms "cotton"balls in Simulant (two phases). A single phase solution is formed in the mixing of oxidized PVA with Tank Farm simulant.. 


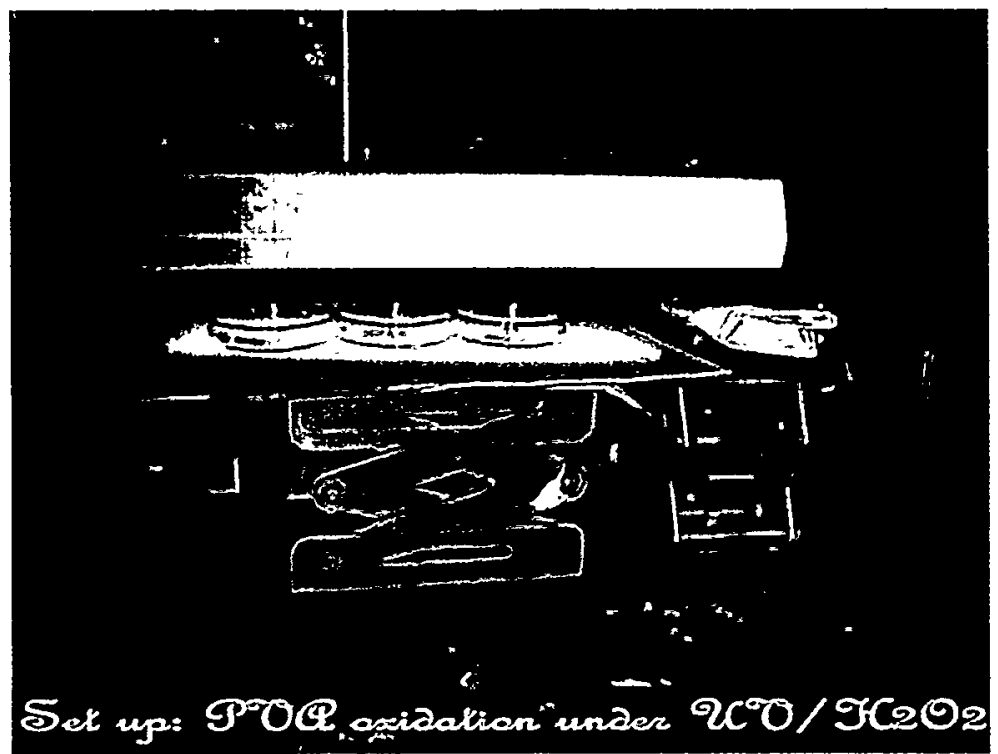

Figure 17. Set up for PVA oxidation under $\mathrm{UV} / \mathrm{H}_{2} \mathrm{O}_{2}$.

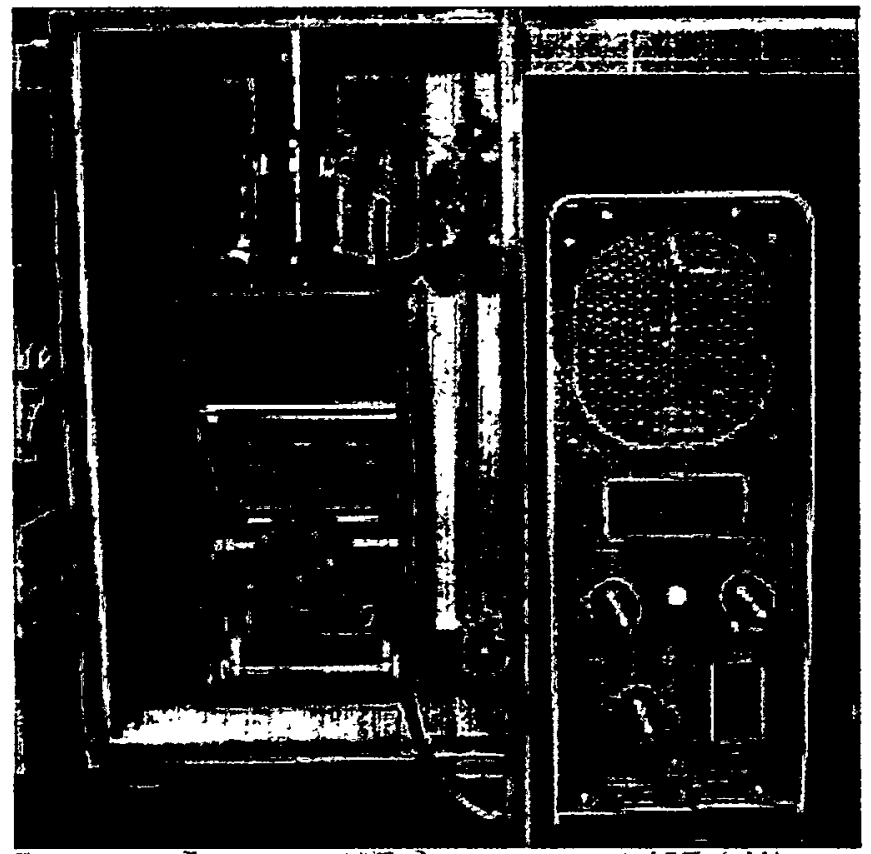

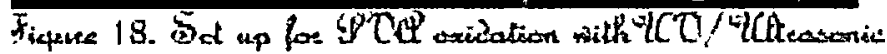

Figure 18. Set up for PVA oxidation: UV photolysis and ultrasonic treatment 


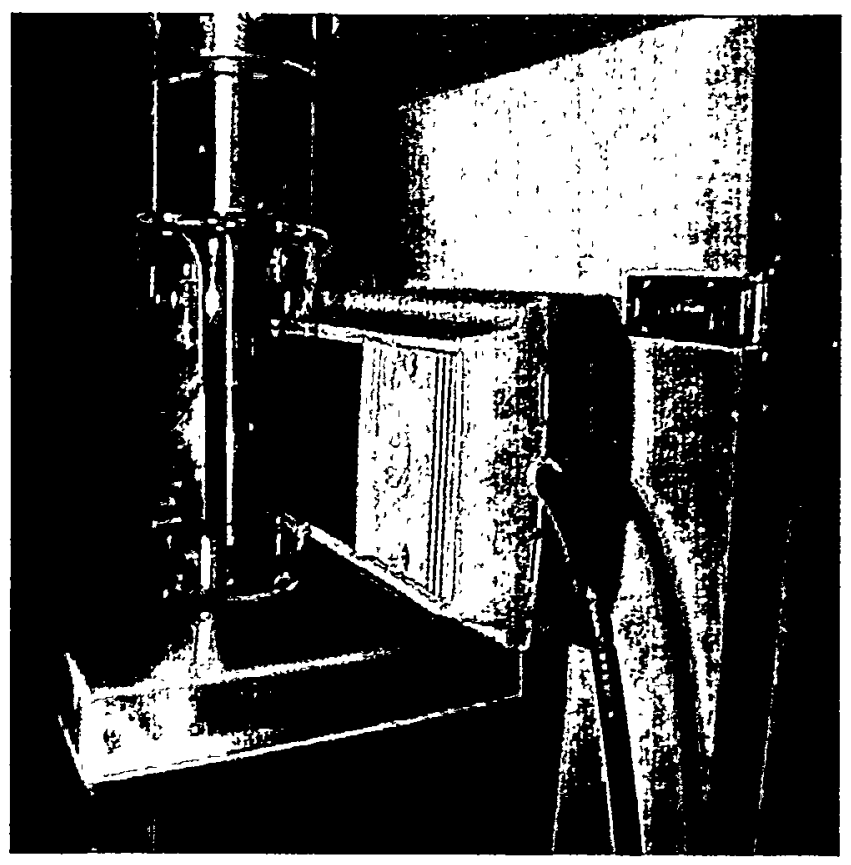

Figure 19. Interior details of Figure 18. UV lamp aligned outside vessel bearing $\mathrm{H}_{2} \mathrm{O}_{2}$ and PVA solution mixture 